Surface Water Quality-Assurance Plan, U.S. Geological Survey, Kentucky Water Science Center, Water Year 2006

Open-File Report 2006-1273 



\section{Surface Water Quality-Assurance Plan, U.S. Geological Survey, Kentucky Water Science Center, Water Year 2006}

By Michael S. Griffin

Open-File Report 2006-1273 


\section{U.S. Department of the Interior \\ DIRK KEMPTHORNE, Secretary \\ U.S. Geological Survey \\ P. Patrick Leahy, Acting Director}

U.S. Geological Survey, Reston, Virginia: 2006

For product and ordering information:

World Wide Web: http://www.usgs.gov/pubprod

Telephone: 1-888-ASK-USGS

For more information on the USGS--the Federal source for science about the Earth, its natural and living resources, natural hazards, and the environment:

World Wide Web: http://www.usgs.gov

Telephone: 1-888-ASK-USGS

Any use of trade, product, or firm names is for descriptive purposes only and does not imply endorsement by the U.S. Government.

Although this report is in the public domain, permission must be secured from the individual copyright owners to reproduce any copyrighted materials contained within this report.

Suggested citation:

Griffin, M.S., 2006, Surface Water Quality-Assurance Plan, U.S. Geological Survey, Kentucky Water Science Center, Water Year 2006: U.S. Geological Survey Open-File Report 2006-1273, 50 p. 


\section{Contents}

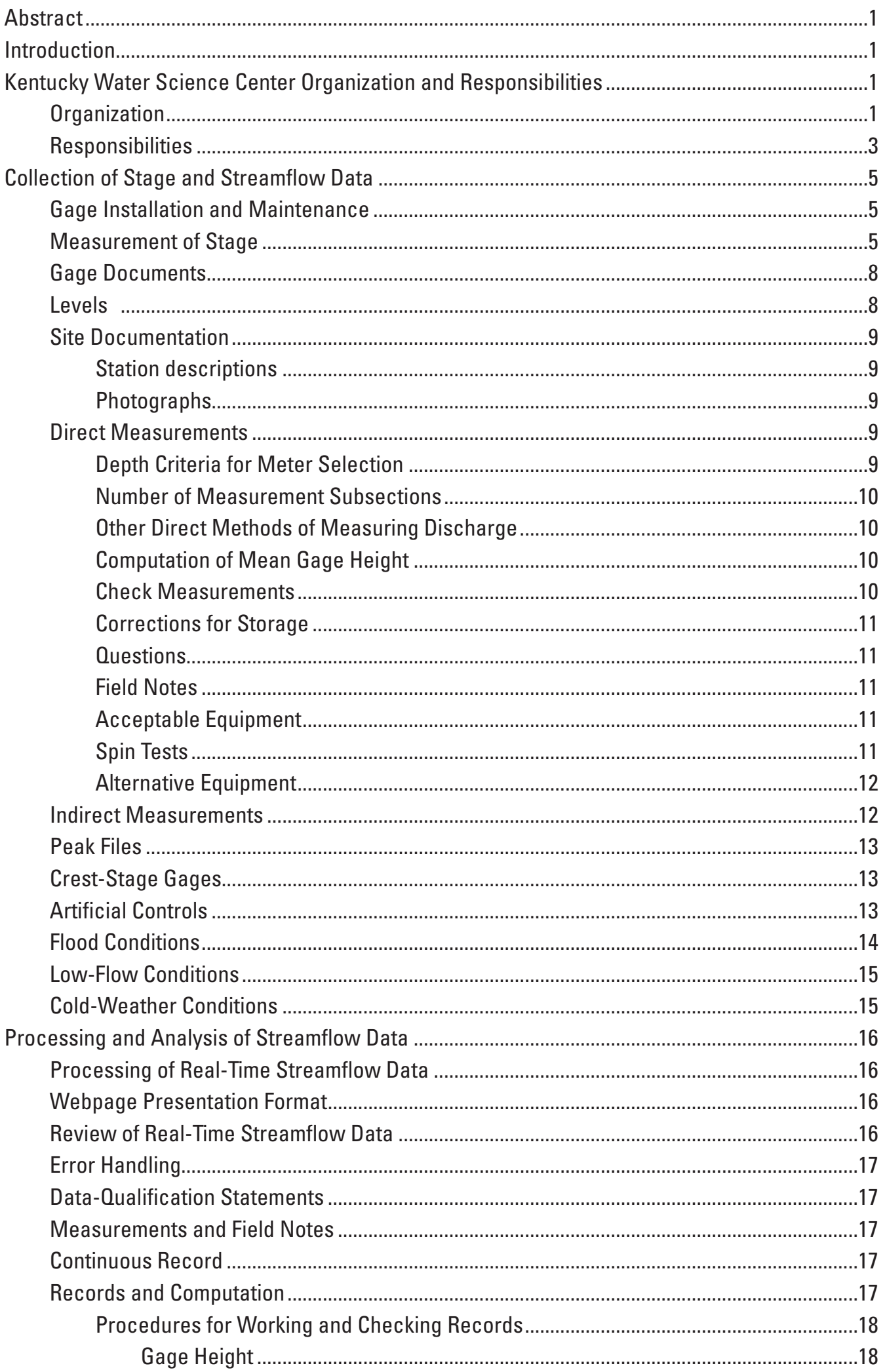




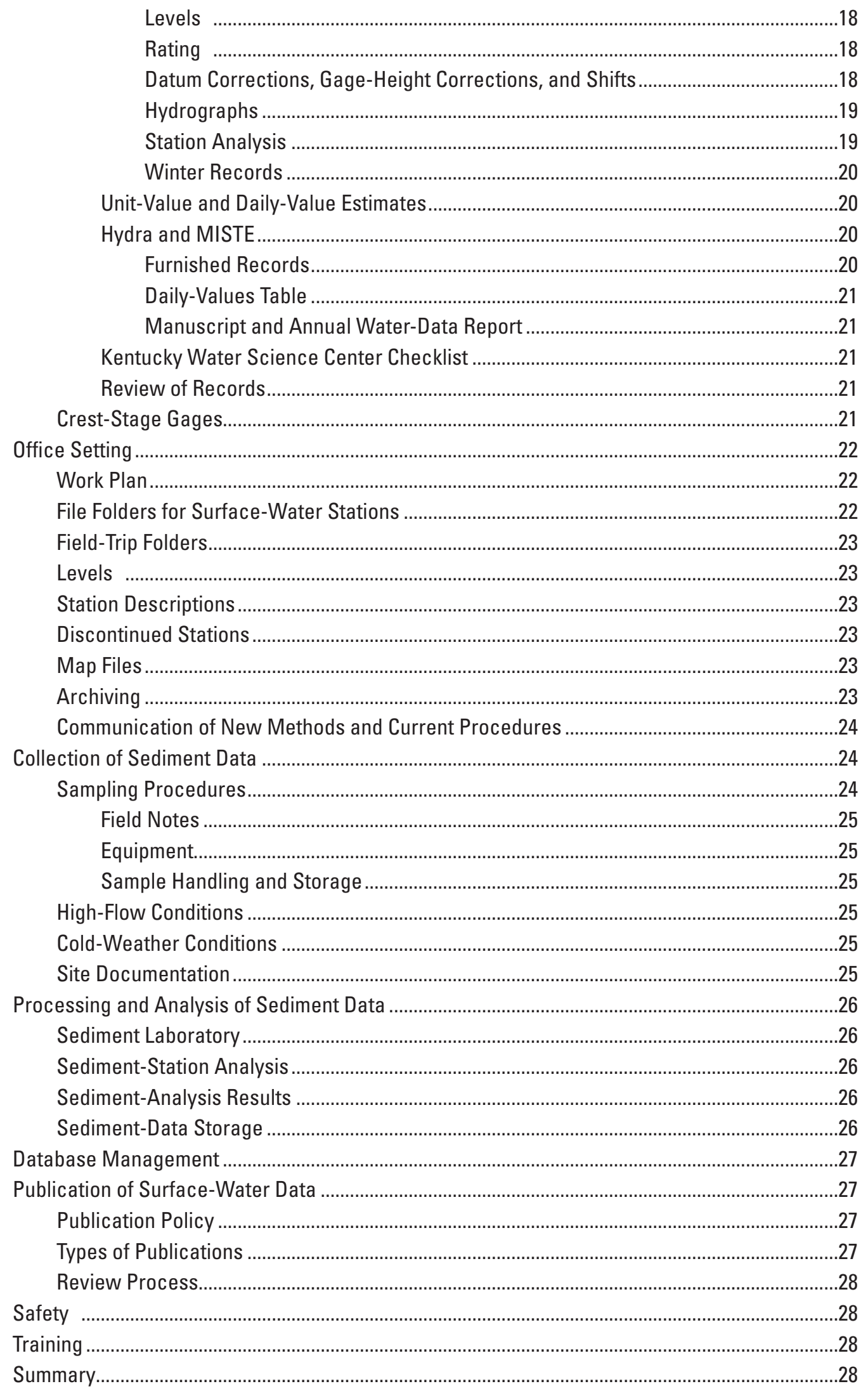


References Cited.

Appendixes:

1. U.S. Geological Survey Technical Memorandums Cited......................................................32

2. Hydrologic Data Section Surface-Water Electronic Archiving Layout ..............................33

3. Example of a Kentucky Water Science Center Station Description ...................................34

4. Example of a Kentucky Water Science Center Station Analysis ........................................36

5. Examples of Records Processing Forms

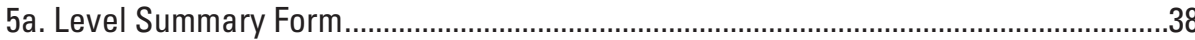

5b. Record Computation Tracking/Checker Form ..........................................................39

5c. Annual Surface-Water Data Reviewer Form .............................................................40

5d. Discharge Measurement/Shift Corrections Form .......................................................41

5e. Datum/Level Corrections Form............................................................................ 42

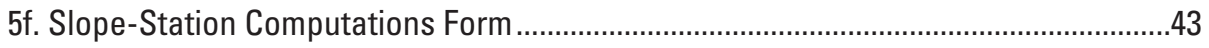

5g. Measurement Log Sheet Form ..............................................................................4

5h. Average Discharge Form..................................................................................... 45

6. Hydroacoustic Instrumentation - Standards, Policies, and Procedures .............................46

\section{Figures}

1. Organizational chart of the U.S. Geological Survey, Kentucky Water Science Center, 2006.......2

2. Map showing streamflow stations in Kentucky, fiscal year 2006 ................................................6

\section{Conversion Factors and Abbreviations}

\section{Inch/Pound to SI}

\begin{tabular}{lll}
\hline \multicolumn{1}{c}{ Multiply } & \multicolumn{1}{c}{ By } & \multicolumn{1}{c}{ To obtain } \\
\hline inch (in.) & Length & \\
foot (ft) & 2.54 & centimeter $(\mathrm{cm})$ \\
mile (mi) & 0.3048 & meter $(\mathrm{m})$ \\
mile, nautical (nmi) & 1.609 & kilometer $(\mathrm{km})$ \\
\hline & 1.852 & kilometer $(\mathrm{km})$ \\
\hline square mile $\left(\mathrm{mi}^{2}\right)$ & Area & \\
\hline & 2.590 & square kilometer $\left(\mathrm{km}^{2}\right)$ \\
\hline foot per second $(\mathrm{ft} / \mathrm{s})$ & Flow rate & meter per second $(\mathrm{m} / \mathrm{s})$ \\
cubic foot per second $\left(\mathrm{ft}^{3} / \mathrm{s}\right)$ & 0.3048 & cubic meter per second $\left(\mathrm{m}^{3} / \mathrm{s}\right)$ \\
\hline
\end{tabular}




\section{Abbreviations}

ADAPS - automated data processing systems

ADCP - acoustic Doppler current profiler

CAP - Culvert Analysis Program

CSG - crest-stage gage

DCP - data collection platform

EDI - equal discharge increment

EWI - equal width increment

FRC - Federal Records Centers

GIS - geographic information system

HDR - high-data-rate

HSS - Hydrologic Surveillance Section

HIS - Hydrologic Investigations Section

HWM - high-water marks

KWSC - Kentucky Water Science Center

$\mathrm{MEWI}$-multiple equal width increment

NARA - National Archives and Records Administration

NWIS - National Water Information System

NWS - National Weather Service

OSW - Office of Surface Water

OWQ - Office of Water Quality

PZF - point-of-zero-flow

$\mathrm{QA}$ - quality assurance

OA Plan - KWSC Surface-Water Quality-Assurance Plan

Qm - discharge measurement

RMs - reference marks

SAC - Slope Area Computation Program

SEWI - single equal width increment

TWRI - Techniques of Water-Resources Investigations

USACE - U.S. Army Corps of Engineers

USGS - U.S. Geological Survey

UWI - unequal width increment

WRD - Water Resources Division/Discipline

WSPRO - Water-Surface Profile

WWG - wire-weight gage measure 


\title{
Surface Water Quality-Assurance Plan, U.S. Geological Survey, Kentucky Water Science Center, Water Year 2006
}

\author{
By Michael S. Griffin
}

\begin{abstract}
This Surface Water Quality-Assurance Plan documents the standards, policies, and procedures used by the Kentucky Water Science Center for activities related to the collection, processing, storage, analysis, and publication of surface-water data.
\end{abstract}

\section{Introduction}

The U.S. Geological Survey (USGS) was established by an act of Congress on March 3, 1879, to provide a permanent Federal agency to perform the systematic and scientific "classification of the public lands, and examination of the geologic structure, mineral resources, and products of the national domain." Surface-water activities in the Kentucky Water Science Center (KWSC) are part of the USGS overall mission of appraising the Nation's water resources. Surface-water information, including streamflow, stage, and sediment data, is used at the Federal, State, and local levels for resources planning and management.

The purpose of the KWSC Surface Water Quality-Assurance Plan (QA Plan) is to document the standards, policies, and procedures used by the KWSC for activities related to the collection, processing, storage, analysis, and publication of surface-water data. This plan identifies responsibilities for ensuring that stated policies and procedures are implemented. The plan also serves as a guide for all KWSC personnel involved in surface-water activities and as a resource for identifying memorandums, publications, and other literature that describe, in more detail, associated techniques and requirements.

The scope of this report includes discussions of the policies and procedures followed by the KWSC for the collection, processing, analysis, storage, and publication of surfacewater data. Specific types of surface-water data include stage, streamflow, sediment, and basin characteristics. In addition, issues related to the management of the computer database and employee safety and training are presented. Although procedures and products of interpretive projects are subject to the criteria presented in this report, specific interpretive projects are required to have a separate and complete quality-assurance plan.

Throughout the QA Plan, various Water Resources Division (currently (2006) Discipline) (WRD) and Office of Surface Water (OSW) memorandums are cited; these memorandums are listed in Appendix 1.

This QA Plan is reviewed and revised at least once every 3 years in order that responsibilities and methodologies are kept current and that the ongoing procedural improvements can be effectively documented.

\section{Kentucky Water Science Center Organization and Responsibilities}

Quality assurance (QA) is an active process. Achieving and maintaining high-quality standards for surface-water data is accomplished by specific actions implemented by specific persons. Errors and deficiencies can result when individuals fail to carry out their responsibilities. Clear and specific statements of responsibilities promote an understanding of each person's duties in the overall process of assuring surface-water data quality.

\section{Organization}

The KWSC has three offices (fig. 1). The main office is in Louisville with two field offices in Paducah and Williamsburg. The main office is organized into operational sections and support units. The operational sections include the Hydrologic Surveillance Section (HSS) (data section) and the Hydrologic Investigations Section (HIS). The support units include the Administrative Section and the Computer Applications Section. The two field offices are organized and managed under the under the leadership of the HSS chief. 


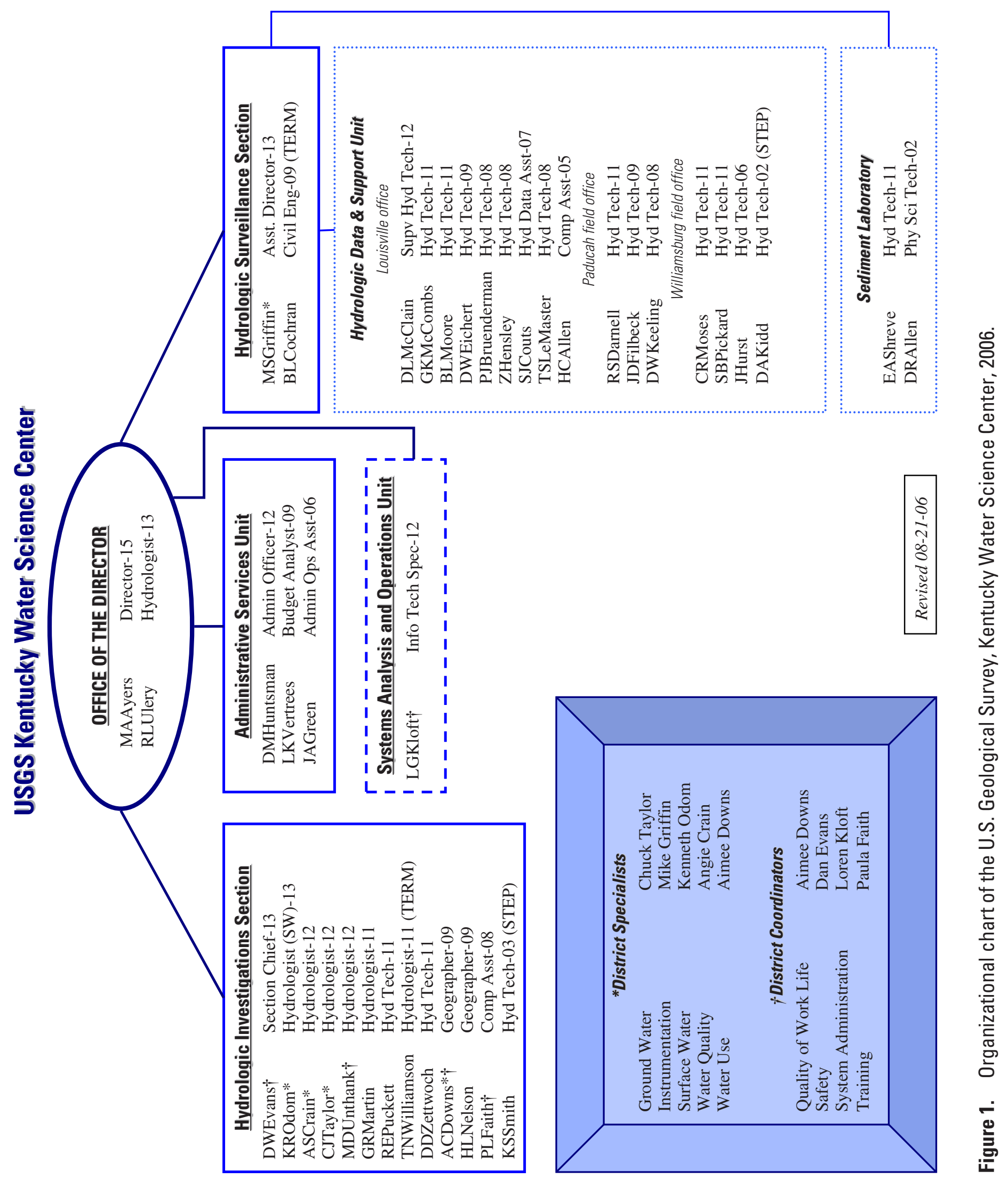




\section{Responsibilities}

Surface-water data-collection personnel within the KWSC are located in the two field offices and the main office in Louisville. All individuals involved in surface-water activities are responsible for implementing quality assurance. Three field office chiefs assume much of the responsibility; however, the HSS chief and the KWSC Director have the overall responsibility. The following is a list of responsibilities of KWSC personnel involved in the collection, processing, storage, analysis, and (or) publication of surface-water data.

The KWSC Director is responsible for-

1. Managing and directing the KWSC program, including all surface-water activities;

2. Ensuring that surface-water activities in the KWSC meet the needs of the Federal Government, the KWSC, State and local agencies, other cooperating agencies, and the public;

3. Ensuring that all aspects of this QA Plan are understood and followed by KWSC personnel. This is accomplished by the Director's direct involvement or through clearly stated delegation of this responsibility to other personnel in the KWSC;

4. Implementing USGS and KWSC safety policies;

5. Keeping KWSC personnel briefed on procedural and technical communications from Regional offices and Headquarters; and

6. Ensuring that all publications and other technical communications released by the KWSC are accurate and are in accordance with USGS policy.

The KWSC HSS chief (Assistant Director) is responsible for-

1. Managing the data-collection program by serving as the principle contact between cooperators and the USGS;

2. Managing the HSS budget to assure the datacollection program operates in a fiscally responsible manner;

3. Ensuring that surface-water data-collection and analysis activities associated with the Kentucky surface-water gaging network conform to the goals and polices of the USGS, the OSW, and the KWSC;

4. Developing the work plans designed to accomplish the work of collecting, processing, analyzing, and storing Kentucky surface-water data; publishing that data in the annual data report; and communicating the contents of those work plans to personnel in the HSS;

5. Ensuring that records for all surface-water data stations are computed correctly, checked, and reviewed;

6. Ensuring that any identified deficiencies associated in the collection, analysis, or publication of surface-water data are corrected and ensuring that improved methods are implemented;

7. Ensuring that all personnel in the KWSC involved in the collection, analysis, and publication of surface-water data receive a copy of the QA Plan and that they are familiar with its contents;

8. Serving as or assigning a Flood Coordinator;

9. Ensuring that the Peak-Flow file is maintained properly by reviewing yearly peaks for each gage;

10. Ensuring that supervised personnel receive appropriate training;

11. Ensuring that supervised personnel are aware of and operate in accordance with safety policies established by the USGS and the KWSC;

12. Ensuring that the surface-water databases are properly maintained and updated;

13. Reviewing all indirect streamflow measurements performed by KWSC personnel;

14. Associated software and writing configurations for telemetry equipment and data loggers; and

15. Inspecting cableways annually.

The KWSC Surface-Water Specialist is responsible for-

- Working with the HSS chief by evaluating surface-water data-collection and analysis methods that are applied in the KWSC and discussing needed improvements of those methods with the HSS chief.

The KWSC Water-Quality Specialist is responsible for-

1. Being knowledgeable of policies and procedures pertaining to the collection, processing, analysis, storage, and publication of sediment data;

2. Reviewing techniques used by KWSC personnel in the collection of sediment data and correcting any deficiencies that are determined;

3. Ensuring that sediment data are correctly stored in the water-quality database; and 
4. Providing guidance and recommendations to ensure needed equipment is available and properly maintained in the HSS vehicles.

The KWSC field office chiefs (Paducah and Williamsburg) are responsible for-

1. Managing and directing the surface-water data program assigned to the field office;

2. Ensuring that all aspects of the QA Plan are understood and followed by field office personnel;

3. Providing guidance and approval of site selection, installation, and operation of all surfacewater gaging stations for their respective field office;

4. Performing technical reviews of surface-water activities performed by their respective field office;

5. Providing resolution of any conflicts or disputes related to surface-water activities in their respective field office; and

6. Overseeing that their respective field office follows the KWSC safety polices.

The KWSC field office chief (Louisville) is responsible for-

1. Assisting the HSS chief in the development of work plans;

2. Being fully conversant with the polices and procedures presented in this report;

3. Ensuring that the collection and analysis of surface-water data are done accurately and with minimal loss of data;

4. Ensuring that field visits are scheduled to allow for adequate numbers of measurements to promote the accurate computation of streamflow records;

5. Reviewing hydrographers field notes after each trip;

6. Annual inspections of HSS vehicles to ensure needed equipment is available and properly maintained and the vehicles are in good condition. A copy of the inspection reports should be filed with the field-trip review forms;

7. Annual inspections of KWSC boats to ensure needed equipment is available and properly maintained and the boats are in good condition. A copy of the inspection reports should be filed with the field-trip review forms; and
8. Overseeing the production of the KWSC annual data report.

The KWSC HSS Hydrologic Technicians are responsible for-

1. Collecting streamflow measurements at high, medium, and low flows to develop and verify ratings;

2. Ensuring that streamflow-gaging stations operate in a manner that results in minimal loss of stage record;

3. Correctly and accurately making streamflow measurements of various types;

4. Installing, servicing, and repairing instruments at streamflow-gaging stations;

5. Storing all data retrieved in the Automated Data Processing Systems (ADAPS) database;

6. Developing ratings, computing streamflow records, and writing station descriptions and analyses in a timely manner;

7. Reviewing data from field stations that are displayed on the website on a daily basis when in the office.

8. Maintaining their assigned field vehicle;

9. Helping construct streamflow-gaging stations;

10. Surveying station levels and establishing and periodically confirming elevations of appropriate reference marks in accordance with USGS surveying procedures; and

11. Being fully conversant with polices and procedures presented in this report.

The KWSC Surface-Water Database Administrator is responsible for-

1. Ensuring software is properly maintained, including updates;

2. Creating all new site files in the database; and

3. Checking the function of ADAPS, remote data access software, and the Internet data-presentation programs.

The KWSC Safety Officer is responsible for-

1. Assisting the Director in implementing USGS and KWSC safety policies;

2. Being a resource for KWSC personnel seeking safety-related information; and

3. Assisting the Director in making safety information and training available to KWSC personnel. 


\section{Collection of Stage and Streamflow Data}

Many of society's daily activities including industry, agriculture, energy production, waste disposal, and recreation, are closely linked to streamflow and water availability; therefore, reliable surface-water data are necessary for planning and resource management. The collection of stage and streamflow data is a primary component of the ongoing operation of streamflow-gaging stations (hereinafter referred to as gaging stations) and other water-resource studies performed by the USGS and the KWSC (fig. 2).

The objective of operating a gaging station is to obtain a continuous record of stage and discharge at the site (Carter and Davidian, 1968, p. 1). A continuous record of stage is obtained by installing instruments that measure and record water-surface elevation in the stream. Streamflow measurements are made at periodic intervals to define or verify the stage-discharge relation and to define the time and magnitude of variations in that relation.

All personnel involved in the collection of stage and streamflow data are informed of and follow the surface-water data-collection policies and procedures established by the USGS and the KWSC. The highest priority in collecting streamflow data is employee safety.

Each hydrologic technician running surface-water field trips has their field notes and streamflow measurements reviewed by their respective field office chief upon returning from the field. The review should be documented on the standard review form.

\section{Gage Installation and Maintenance}

Proper installation and maintenance of gaging stations are critical activities for ensuring quality of streamflow-data collection and analysis. Effective site selection, correct design and construction, and regular maintenance of a gage can make the difference between efficient and accurate estimation of streamflows and time-consuming, poor estimations of flow.

Sites for installation of gaging stations are selected with the intent to meet the purpose of each specific gage. Additionally, sites are selected with the intent of achieving, to the greatest extent possible, ideal hydrologic conditions. Criteria that describe the ideal gaging-station site are listed in Rantz and others (1982, p. 5). These criteria include unchanging natural controls that promote a stable stage-discharge relation, a satisfactory reach for measuring discharge throughout the range of stage, and the means for safe and efficient access to the gage and measuring location. Other aspects of controls considered by KWSC personnel when planning gage-house installations include those discussed in Kennedy (1984, p. 2).

The HSS chief, with assistance from the field office chiefs, is responsible for selecting sites for new gaging stations. The process of site selection includes discussions with cooperators on the purpose of the gage and analysis of terrain with the use of topographic maps, field reconnaissance, and a file search to determine if discontinued stations or partialrecord stations existed previously in the area.

The HSS chief is responsible for ensuring proper documentation of agreements with property owners is obtained, approval of site design, and inspection and approval of the completed installation. The field office chiefs are responsible for construction of gages.

A program of careful inspection and maintenance of gages and gage houses promotes the collection of reliable and accurate data. Allowing the equipment and structures to fall into disrepair can result in unreliable data and safety problems.

It is KWSC policy that all field personnel perform a visual inspection of sites during each visit by comparing the inside and outside gage readings. In addition, all equipment is inspected to ensure it is in proper working order. Checking battery conditions, the physical structure, locking mechanisms, and the general working order of the gage are required.

The intakes are flushed or the orifices are purged during each regular visit for sites containing stilling wells or orifice gas-bubblers to prevent the buildup of mud or the clogging of intakes. Other maintenance activities performed on a regular basis include checking and replacing batteries and nitrogen cylinders; replacing the desiccant in the pumping systems; cleaning and painting the gage house; and cutting brush near the gage house, bridge, and tethered boat measurement section or the cableway.

The KWSC's goal is to achieve a continuous and complete record of stage at each gaging station. Deficiencies are documented orally to the field office chief or on an inspection sheet. It is the responsibility of each hydrographer to ensure that gages and gage houses are kept in good repair and that any deficiency documented be corrected immediately. To ensure these responsibilities are carried out, it is the policy of the KWSC that each gage is visited by at least two different hydrographers each year for quality-assurance purposes. It is the responsibility of the three field office chiefs to provide guidance and assistance on attaining the appropriate level of maintenance.

\section{Measurement of Stage}

Many types of instruments are available for measuring the stage at gaging stations. There are non-recording gages (Rantz and others, 1982, p. 24) and recording gages (Rantz and others, 1982, p. 32). It is OSW policy that surface-water stage records at stream sites be collected with instruments and procedures that provide sufficient accuracy to support computation of discharge from a stage-discharge relation, unless greater accuracy is required, because many of the uses for stage data cannot be predicted (Office of Surface Water Technical Memorandum No. 93.07). 


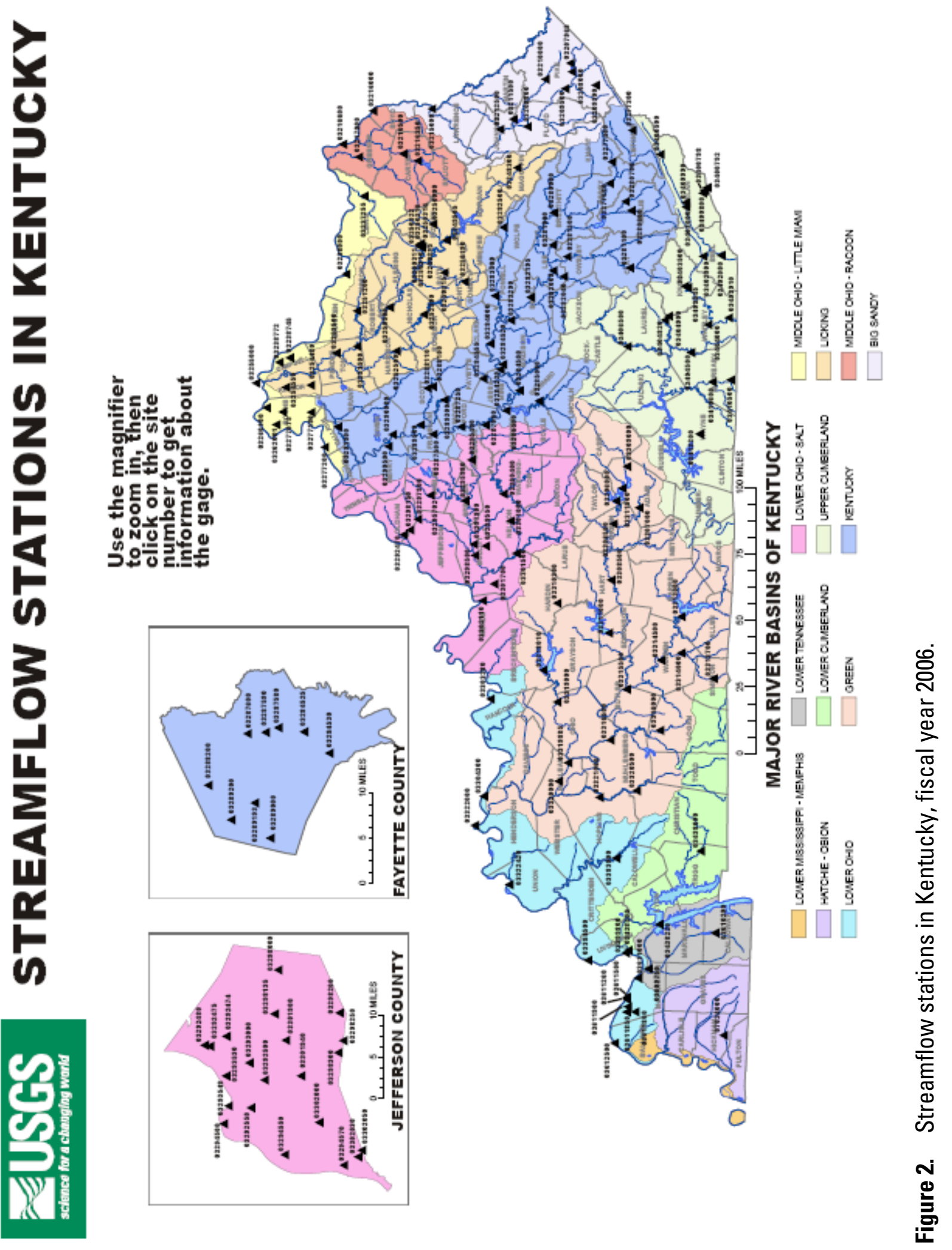


In general, operation of gaging stations for the purpose of determining daily discharge includes the goal of collecting stage data at the accuracy of + or $-0.01 \mathrm{ft}$ (Office of Surface Water Technical Memorandum No. 89.08). An explanation of WRD policy on stage-measurement accuracy as it relates to instrumentation is provided in Office of Surface Water Technical Memorandum No. 93.07.

The types of instrumentation installed at any specific gage house operated by the KWSC is dependent upon the KWSC's and the cooperators needs for data, telemetry, hydraulic conditions, frequency of update, range of stage, availability of power and phone lines, and other specific data needs associated with the station. The KWSC's data network is 100 percent real-time or near real-time. Types of water-level recorders operated by personnel in the KWSC include those produced by Design Analysis and Vaisala. Other equipment being used to assist in the data-collection effort includes Handar and Design Analysis shaft encoders; Parascientific, Sutron, and Design Analysis pressure transducers; and Design Analysis Radar units.

The hydrographers are responsible for determining the types of sensors and data loggers that are operating at each gaging station. The KWSC is in the process of standardizing its data-collection interval times. All USGS gages are setup to collect stage data at least every 15 minutes; however, many are setup for 5-minute intervals. The U.S. Army Corps of Engineers (USACE) - Louisville District has given the KWSC permission to change their logging intervals to 15 minutes. Discussions are ongoing with the USACE Huntington and Nashville Districts to change their sites to 15 minutes. Ensuring that new equipment has been installed correctly is the responsibility of the hydrographer who installed the equipment with guidance from the HSS chief or field office chief. Proper maintenance of gage instrumentation or replacement, if appropriate, of equipment is the responsibility of all field personnel who service the gage.

Accurate stage measurement requires not only accurate instrumentation but also proper installation and continual monitoring of all system components to ensure the accuracy does not deteriorate with time (Office of Surface Water Technical Memorandum No. 93.07). To ensure that instruments located within the gage house record water levels that accurately represent the water levels of the body of water being investigated, "inside" and "outside" water-level readings are obtained by independent means. For example, at a stilling well gaging station, all recording gages are calibrated to agree with an electric-tape gage, inside staff plate, float-tape indicator, or a reference point used for tape downs. Independent outside readings are made with a wire-weight gage, outside staff plates, or an outside reference point used for tape downs to the stream. At pressure transducer sites and radar sites, the outside gages are used to calibrate the inside gage. The inside gage readings do not always equal outside readings, especially if the gages are not in the same pool at all ranges of stage. It is possible during low flows that the inside and outside gages may not match because the different sensors may be isolated from each other and in different pools. It is important to document when the outside readings are taken from a different pool and do not match the inside readings. The relation between the two readings should be consistent. If there is inconsistency between the two readings, the problem should be investigated and resolved. At stations equipped with a stilling well, the base or reference gage usually is an instrument installed inside the gage house, and other gages are installed outside the gage house to indicate whether the intakes are operating properly (Rantz and others, 1982, p. 53 and 64). At pressure transducer and radar sites, the outside gage is considered the reference gage. The reference gage is identified in the station description at all gaging stations.

Personnel servicing the gage are responsible for comparing inside and outside readings during each site visit to determine if the outside water level is represented correctly by the gages. If a discrepancy is identified, the personnel servicing the gage are responsible for thoroughly documenting the problem on the field-note sheet and correcting the problem immediately or contacting their field office chief or the HSS chief so that corrective actions can be taken.

The hydrographer who services the instrumentation at a gaging station is responsible for ensuring that it is properly serviced and calibrated. This responsibility is accomplished by reviewing the field notes during the trip review or having someone else visit the gage in a timely manner. When deficiencies are identified, the hydrographer should correct the deficiency immediately or replace the faulty equipment. Each field person and field vehicle should be supplied with adequate tools, spare parts, or replacement equipment when visiting a troubled site. If a separate trip is required, it should be done as soon as is practicable. Individuals who have questions related to the calibration and maintenance of water-level recorders should contact an experienced hydrographer, the field office chief, or the HSS chief. All pressure-transducer sites and radar sites have a crest-stage gage (CSG) installed to verify the peak recorded by the data logger and stage sensor or record the peak when the data logger radar on pressure transducer fails. If a CSG or data logger fails to record the peak stage, the hydrographer should flag high-water marks (HWM) so that an elevation can be determined at a later date using surveying equipment. It is the responsibility of the hydrographer to check the CSG intakes and ground-cork level to ensure that all peaks have the capability to be recorded. All stilling-well sites have 'min-max' indicators installed on the float tape to help verify the range of stages between visits. The hydrographer is to reset these 'min-max' indicators during their scheduled site visit. 


\section{Gage Documents}

It is KWSC policy that certain documents are placed in each gage house for keeping an on-site record of observations, equipment maintenance, structural maintenance, and other information helpful to field personnel. Documents maintained at each gage house include the following:

1. a current tabular rating table

2. a current graphical rating curve showing shifts; measurements are to be plotted before leaving the site

3. the current station description listing all gages and reference marks at the site and associated elevations, locations of measurement cross sections, information related to extreme events including the potential for channel storage between the gages (slope stations), location of the low-water control, and other information

4. a $\log$ (Form 9-207) updated by field personnel during each site visit, which describes control conditions and lists gage readings, measurement values, location of measurement, and gage and equipment maintenance

5. a copy of the level summary sheet

6. a job-hazards analysis

7. a traffic-control plan

8. a calendar with Julian dates

It is the responsibility of the hydrographer who maintains the gage on a regular basis to exchange outdated material with updated gage documents, as needed. When field personnel visit a gage house and identify a need to update one or more of the documents, that individual should document the need using a miscellaneous note sheet and inform the field office chief upon his/her return to the office. Individuals having questions related to what documents should be kept in a gage house, when the documents should be replaced with updated documents, or appropriate methods of appending logs or plotting measurements should contact the field office chief or the HSS chief.

\section{Levels}

The various gages at a gaging station are set to register the height of water surface above a selected level reference surface called the gage datum. The gage's supporting structures-stilling wells, backings, shelters, bridges, and other structures - tend to settle or rise as a result of earth movement, static or dynamic loads, vibration, or battering by floodwaters and flood-borne ice or debris. Vertical movement of a structure makes the attached gages read too high or too low and, if the errors go undetected, may lead to increased uncertainties in streamflow records. Leveling, a procedure by which surveying instruments are used to determine the differences in elevation between points, is used to set the gages and to check them from time to time for vertical movement (Kennedy, 1990, p. 1). Levels are run periodically to all bench marks, reference marks, reference points, and gages at each station for the purpose of determining if any datum changes have occurred (Rantz and others, 1982, p. 545).

It is KWSC policy that level information including sea level elevations is collected at newly established gaging stations at the time of construction and is run each year for the first 3 years. If stability is not seen during the first 3 years, then annual levels will continue for the next 2 years. Levels are run at established gaging stations and CSG's every 3 to 5 years if the stations have proven to be stable. Gages are reset to agree with levels when the levels indicate a 0.015 - $\mathrm{ft}$ or more vertical change. When gages are reset, field personnel document the reset by writing the "found" and "left" gage readings on the level-note sheet and the time associated with each reading. Outside water-surface elevations and the associated time are determined with level-instrument readings each time levels are run at a gaging station and are written on the note sheet.

When levels are run, each gage or established mark must have two independent shots, requiring a minimum of two instrument setups to complete a loop or circuit. The level loop must close to the starting elevation within 0.003 - $\mathrm{ft}$ times the square root of the number of turning points (see Kennedy, 1990, p. 4), or the level run is considered invalid and the entire set of levels must be run again. No matter how many turning points there are, the level loop must close to within 0.015 or the level loop is considered invalid and the entire set of levels must be run again.

Levels are run by use of field methods and documentation methods described in Kennedy (1990). Level procedures followed by KWSC personnel pertaining to circuit closure, instrument reset, and repeated use of turning points are described in Kennedy (1990) and in Office of Surface Water Technical Memorandum No. 93.12. When practical, at least three reference marks (RMs) are established for all gaging stations. At least one of the RMs should be established away from the bridge, cableway, and the gage-house foundations. When a gaging station is established, a "reference" or "base" gage will be designated; all gage heights will be referred to this gage. The level instruments are kept in proper adjustment by ensuring accuracy using the peg test described in Kennedy (1990, p 13). The peg tests are done before each set of levels is run or at the beginning of a leveling trip. Results of the peg tests are kept in a logbook, which is housed in the HSS. A copy of the latest peg tests should be kept with the instrument; if the instrument fails the peg tests, another instrument will be used in its place.

It is the responsibility of the field crew chief or the field office chief to ensure that all field-level notes are checked. The level information is entered in the level-summary form by the person working that station's records or the field office chief. Ensuring that levels are run correctly, all level notes are com- 
pleted correctly, and levels are run at the appropriate frequency is the responsibility of field office chief. The level-summary sheet is stored in the station computation folder and should be reviewed annually.

\section{Site Documentation}

Thorough documentation of qualitative and quantitative information describing each gaging station is required. This documentation, in the form of a station description and photographs, provides a permanent record of site characteristics, structures, equipment, instrumentation, elevations, location, and changes in conditions at each site. Information pertaining to where these forms of documentation are maintained is discussed in the section of this report titled "Office Setting."

\section{Station descriptions}

A station description is prepared for each gaging station and becomes part of the permanent record for each station. It is KWSC policy that the station description is written during the first year of operation. It is the responsibility of the field office chief to ensure that station descriptions are prepared correctly and in a timely manner. Station descriptions are updated annually if needed. It is the responsibility of the field office chief or hydrographers checking or reviewing the station records to ensure that station descriptions are updated as described.

Station descriptions are written to include specific types of information in a consistent format (Kennedy, 1983, p. 2). An example of a KWSC station description is shown in Appendix 3. Types of information included in the station description are location, when gage was established, drainage area, road logs, datum, cooperator identification, descriptions of equipment and gage structure, the history of the gage, reference marks, bench marks, and is the site affected by regulation and diversion. The latitude, longitude, and drainage area are determined by the KWSC's Geographic Information Systems (GIS) unit or from a 7.5-minute topographic map. The gaging station is plotted on a master set of topographic maps maintained by the KWSC as master file maps. Each station is assigned a downstream-order number. The HSS chief or the Louisville field office chief is responsible for assigning these numbers to all USGS sites in Kentucky. All current station descriptions are written using Microsoft Word and stored in a central computer sub-directory (stat.desc) under the home directory Data/kyproj, which is accessible by all KWSC personnel. Paper copies are kept in the station file in each field office. Station descriptions are written by the hydrographer working the station's surface-water records and checked or reviewed by other hydrographers or the field office chief; station descriptions are updated annually.

\section{Photographs}

Photographs of gaging stations, control sections, reference marks, cableways, upstream and downstream views, road pull-offs for vehicles, and any other pertinent information are made by field personnel for the purpose of documentation. A complete set of photographs is taken during the construction of a gage; each photograph that becomes part of the station record is identified by placing a hardcopy of the photograph in the station file with the name of the site and date marked on the back. Each hydrographer has a digital camera and is encouraged to use it. The files are downloaded to a central computer and backed up weekly.

\section{Direct Measurements}

Direct measurements of discharge are made with any one of a number of methods approved by the USGS.

A current-meter measurement is the summation of the products of the subsection areas of the stream cross section and their respective average velocities (Rantz and others, 1982, p. 80). Procedures used for current-meter measurements are described in Rantz and others (1982, p. 139), Carter and Davidian (1968, p. 7), and Buchanan and Somers (1969, p. 1).

When personnel make measurements of stream discharge, attempts are made to minimize errors. Sources of errors are identified in Sauer and Meyer (1992). These include random errors such as depth errors associated with soft, uneven, or mobile streambeds or uncertainties in mean velocity associated with vertical-velocity distribution errors and pulsation errors. These errors also include systematic errors, or bias, associated with improperly calibrated equipment or the improper use of such equipment.

To minimize these errors, each field trip is assigned to a single hydrographer who runs the trip on a regular basis. At times, two hydrographers will run the field trip, especially the field trips where the acoustic Doppler current profiler (ADCP) is used to measure streamflow. At least once during the year, it is the desired practice of the HSS to have a different individual run the field trip and thereby identify and minimize the potential systematic errors. Field trips are rotated between hydrographers every 2 to 3 years.

KWSC policies related to the measurement of discharge by wading the stream or by the use of a boat are in accordance with USGS policies, include the following: (see Appendix 6, Hydroacoustics Instrumentation - Standards, Policies, and Procedures).

\section{Depth Criteria for Meter Selection}

Kentucky personnel select the type of current meter to be used for each discharge measurement based on criteria provided by Office of Surface Water Technical Memorandum No. 85.14. Meters are used with caution when a measurement must be made in conditions outside the ranges of the method 
provided by OSW. Any deviations from those criteria are noted and the measurement accuracy is downgraded accordingly.

The Sontek Flowtracker is the primary tool used for most wading measurements. The depth-sampling convention is the same as the Price AA meter. Flowtrackers, however, do not have a minimum-depth requirement (with the exception that the probes must be totally submerged). Furthermore, singlevelocity samples (.6) are used for depths below $2.5 \mathrm{ft}$, and double-velocity samples (.2 and .8) are used for depths greater then $2.5 \mathrm{ft}$. Therefore, a Flowtracker can be used for all depth scenarios for wading measurements in place of the Price AA and pygmy meters.

The Flowtracker may not work in weed- or leaf-choked channels or in clear streams where small signal-to-noise ratios may be a factor. KWSC personnel carry conventional meters (Price AA and pygmy) and use them when situations like these occur. The Flowtracker should be used when velocities in more than five sample sections of a measurement are less than $.2 \mathrm{ft} / \mathrm{s}$.

The ADCP is used in manned boats or with the tetheredboat system when flows are greater than can be safely waded. Normally, depths greater than $3 \mathrm{ft}$ are measured from a bridge using a boom truck equipped with conventional meters or from a tethered boat using the ADCP. A manned boat, equipped with an ADCP, is used on larger rivers to make discharge measurements.

Hydrographers carry a pygmy and Price AA meter for wading and (or) bridge/cableway measurements. These meters are to be maintained and spin-tested according to the policies described in the "Acceptable Equipment" section of this QA Plan. For a conventional meter, the following criteria should be followed. The Price AA meter may be used to make direct streamflow measurements when depths average $1.5 \mathrm{ft}$ or greater. When depths are less than $2.5 \mathrm{ft}$, a single velocity measurement is taken at 0.6 total depth. When depths are greater than $2.5 \mathrm{ft}, 0.2$ and 0.8 measurements are used. These guidelines all assume standard velocity profiles. If the bottom velocity is greater than the top velocity, a standard profile does not exist. In that case, a non-standard profile of $0.2,0.6$, and 0.8 measurements should be taken to determine the mean velocity for that vertical. When average depths are less than $1.5 \mathrm{ft}$, the pygmy meter or Flowtracker is used. Meter selections are based upon the guidance found in Office Surface Water Technical Memorandum No. 85.14, Buchanan and Somers (1969), and Rantz and others (1982).

When using conventional meters, it is recommended that a meter change is not made during a measurement in response to the occurrence of two or more subsections in a single measurement cross section that exceed the stated ranges of depth and velocity. If the streamflow in the affected area represents less than 10 percent of the total streamflow, then the error associated with these few subsections will not affect the error of the measurement. The hydrographer making the measurement will use his/her discretion whether to change meters in situations where overflow conditions create a secondary chan- nel, which effectively creates a different measurement cross section.

\section{Number of Measurement Subsections}

The spacing of observation verticals in the measurement section can affect the accuracy of the measurement (Rantz and others, 1982, p. 179). The USGS criteria are that observations of depth and velocity be made at a minimum of about 30 verticals, which are normally necessary so that no more than 5 percent of the total flow is measured in any one vertical. Even under the worst conditions, the discharge computed for each vertical should not exceed 10 percent of the total discharge and ideally not exceed more than 5 percent (Rantz and others, 1982, p. 140). Exceptions to this policy are allowed in circumstances where accuracy would be sacrificed if this number of verticals were maintained, such as for measurements during rapidly changing stage (Rantz and others, 1982, p. 174). Fewer verticals than ideal sometimes are used for very narrow streams. Measurement of discharge is a sampling process, and the accuracy of sampling results decreases markedly when the number of samples is less than 25 .

\section{Other Direct Methods of Measuring Discharge}

It is KWSC policy that USGS and OSW techniques and guidelines are followed when discharge measurements are made with any selected method of measurement. These methods include the use of mechanical instruments and other techniques. These methods might include the tracer-dilution method, measurements using float or volumetric techniques, and methods involving portable weirs and flumes. These portable devices are applied according to the methods described in Rantz and others (1982), Buchanan and Somers (1969), and Kilpatrick and Schneider (1983). When these methods are employed, it is the responsibility of the hydrographer to inform the field office chief or the HSS chief. The HSS chief will review the methods being used by the hydrographers to ensure correctness of procedures and results.

\section{Computation of Mean Gage Height}

KWSC personnel use procedures presented in Rantz and others (1982, p. 170) for the computation of mean gage height during a discharge measurement. Mean gage height is one of the variables used in describing the stage-discharge relation at a streamflow-gaging site. The mean gage height for a streamflow measurement is based on the reference gage.

\section{Check Measurements}

A second streamflow measurement is made for checking a first streamflow measurement when the first measurement differs from the rating by more than 5 percent and the result of the first measurement is suspect. The results are considered 
suspect if the measurement does not plot within the rating limits, usually good (5 percent), fair ( 8 percent), and poor ( $>8$ percent). A check measurement may not be required if you can document why it plotted off the rating curve. When check measurements are made, the potential for systematic errors are minimized by using methods described in Rantz and others (1982, p. 346). These methods include using another crosssection location, a different meter, and using verticals offset from the original verticals in a bridge or cableway measurement.

\section{Corrections for Storage}

Corrections for storage applied to measured discharges for defining stage-discharge relations are those discussed in Rantz and others (1982, p. 177) and in Office of Surface Water Technical Memorandum No. 92.09.

\section{Questions}

Personnel who have questions concerning the appropriate procedures for making stage and discharge measurements should address their questions to the field office chief or the HSS chief.

\section{Field Notes}

Thorough documentation of field observations and data-collection activities performed by field personnel is a necessary component of surface-water data collection and analysis. To ensure that clear, thorough, and systematic notations are made during field observations, discharge measurements are recorded by field personnel on measurement series Form 9-275. Notations are made in the manner presented in Buchanan and Somers (1969). Original observations, once written on the note sheet, are not erased. Original data are corrected by crossing the value out then writing the correct value. Some examples of original data on a discharge-measurement note sheet include gage readings, depth, and times. Examples of information on a discharge-measurement note sheet that is derived from original data, but not in itself original data, include computed total streamflow, mean gage height, measurement number, stream width, and mean velocity. Derived data can be erased for the purpose of correction.

It is KWSC policy that all non-ADCP streamflow measurements are calculated in their entirety before the hydrographers leave the field site, unless emergency evacuation is required for safety reasons. Information required to be included by field personnel on the measurement note sheet includes, at minimum, the initials and last name of each fieldcrew member, date, times associated with gage readings and other observations, gage readings, spin-test comments, crosssection width and area, mean velocity mean gage height, and total streamflow. ADCP streamflow measurements have edge estimates and subsectioning calculated at a later time, usually in the office.

Notations associated with miscellaneous surface-water data-collection activities are documented on the standard miscellaneous note sheet (Miscellaneous Field Notes - Form 9-275-D, January 1988). All miscellaneous notes are required to include, at minimum, initials and last name of each fieldcrew member, date, time associated with observations, purpose of the site visit, and a detailed description of the observations.

A review of field note sheets by the field office chief is required after each field trip and annually during the surface-water records review. Deficiencies found in the content, accuracy, clarity, or thoroughness of field notes are identified and communicated orally to all hydrographers in the HSS. The deficiencies are remedied by the field office chief providing specific instructions to individuals who fail to record notations that meet USGS and KWSC standards.

\section{Acceptable Equipment}

Equipment used by the KWSC for the measurement of surface-water streamflow has been found acceptable by the USGS through use and testing. An array of acceptable equipment for measuring streamflow includes current meters (conventional and acoustic), calculators, timers, wading rods, bridge cranes, tag lines, and others (Rantz and others, 1982, p. 82; and Smoot and Novak, 1968). Although an official list of acceptable equipment is not available, Buchanan and Somers (1969), Carter and Davidian (1968), and Edwards and Glysson (1988) discuss the equipment used by the USGS.

The meters most commonly used by KWSC personnel for measuring surface-water discharge are the Price AA current meter, the Price pygmy current meter, the Flowtracker, and the ADCP. The hydrographer using the meter is responsible for its condition and maintenance. Methods followed by KWSC personnel for inspecting, repairing, and cleaning these meters are described in Smoot and Novak (1968, p. 9); Rantz and others (1982, p. 93); and Buchanan and Somers (1969, p. 7).

The ultimate responsibility for the good condition and accuracy of a current meter is that of the field personnel using it (Office of Surface Water Technical Memorandum No. 89.07). A timed spin test made a few minutes before a measurement does not ensure that the meter will not become damaged or fouled during the measurement. Field personnel must assess apparent changes in velocity or visually inspect the meter periodically during the measurement to ensure that the meter continues to remain in proper operating condition. The KWSC follows the care and maintenance procedures of vertical-axis current meters as described in the Office of Surface Water Technical Memorandum No. 99.06.

\section{Spin Tests}

It is KWSC policy that timed spin tests are required prior to and at the end of each field trip. Spin-test results are 
documented in a logbook kept in the HSS. If a meter is not normally used, it must be checked at least once during the year and those results should be recorded in the logbook. This logbook is part of the archived data of WRD (Office of Surface Water Technical Memorandum No. 89.07). Repairs are made to meters when deficiencies are identified through the spin test or inspection. Quarterly review of this logbook is required by each field office chief. If deficiencies are observed during review of the logbook, appropriate field personnel are informed through oral and written (email) communication and the problems are corrected immediately.

In addition to the timed spin tests performed prior to field trips, field personnel are required to inspect the meter before and after each measurement to ensure the meter is in good condition, the cups spin freely, and the cups do not come to an abrupt stop. Descriptive notations are made at the appropriate location on the field note sheet concerning the meter condition, such as "OK" or "free" or other such comments. To ensure that field personnel carry out their responsibilities in maintaining the equipment they use, the equipment is inspected annually by the field office chief. If deficiencies are identified, it is the responsibility of the hydrographer that uses the equipment in the field to correct the problem. It is the responsibility of the field office chiefs to determine if a deficiency affected the quality of the data collected when defective equipment was used.

\section{Alternative Equipment}

The development of new technology sometimes involves collection of surface-water data with alternative equipment that has not been fully accepted by WRD. To demonstrate the quality of surface-water data collected with alternative equipment, thorough documentation of procedures and observations must be maintained.

Alternative equipment used by the KWSC includes the Design Analysis Radar gage. The KWSC has many of these units installed at USGS and USACE gages. When possible, data are collected in conjunction with the equipment it was replacing. In most cases, the radar gage worked as well as the encoder or pressure transducer it was replacing.

The HSS chief is responsible for ensuring that alternative equipment is used correctly and documentation is comprehensive and is stored correctly.

\section{Indirect Measurements}

In many situations, especially during floods, it is impossible or impractical to measure peak discharges by use of a current meter or ADCP. There may not be sufficient warning for personnel to reach the site to make a direct measurement, or physical access to the site during the event may not be feasible.

A peak discharge determined by indirect methods is, in many situations, the best available means of defining the upper portions of the stage-discharge relation at a site. Measurements of peak discharges by indirect methods are important forms of data, because extrapolation of a stage-discharge relation, or rating, more than two times the measured discharge at a gaging station is undesirable and may be unreliable (Rantz and others, 1982, p. 334).

The KWSC follows data-collection and computation procedures presented in Benson and Dalrymple (1967). That report includes policies and procedures related to site selection, field survey, identification of high-water marks, the selection of roughness coefficients, computations, and the written summary. The KWSC also follows procedures for measurement of peak discharge by indirect methods presented in Rantz and others (1982, p. 273).

In addition to the general procedures presented in Benson and Dalrymple (1967), the KWSC follows guidelines presented in other reports that describe specific types of indirect measurements suited to specific types of flow conditions. The slope-area method is described in Barnes (1967) and Dalrymple and Benson (1967). The USGS applies the Manning equation in application of the slope-area method. Procedures for selecting the roughness coefficient are described in Arcement and Schneider (1989). The computer-based tool, Slope Area Computation Program (SAC), available to assist in computations of peak discharge with the slope-area method, is discussed in Office of Surface Water Technical Memorandum No. 83.07. Procedures for the determination of peak discharge through culverts, based on a classification system that delineates six types of flow, is described in Bodhaine (1982). The computer-based tool, Culvert Analysis Program (CAP), available to assist in computations of peak discharge at culverts, is discussed in Office of Surface Water Technical Memorandum No. 83.07. At sites where open-channel width contractions occur, such as flow through a bridge structure, peak discharge can be measured with methods described in Matthai (1967) and with the Water-Surface Profile (WSPRO) computation model (Shearman, 1990). Debris-flow conditions, which are most common in small mountainous basins, are discussed in Office of Surface Water Technical Memorandum No. 92.11.

Determinations of water-surface profiles along a stream channel in association with selected discharges are made when studies are performed that involve delineations of flood plains or when extensions are made to stage-discharge relations at streamflow sites. KWSC personnel are required to follow the procedures associated with step-backwater methods described in Davidian (1984). The computer-based tool used for assisting in the computations of water-surface profiles with stepbackwater methods, WSPRO, is discussed in Office of Surface Water Technical Memorandum No. 87.05.

General guidelines followed by KWSC personnel when making indirect measurements include those discussed in Office of Surface Water Technical Memorandum No. 92.10 and in Shearman (1990). Violation of any one of the general guidelines does not necessarily invalidate an indirect measurement (Office of Surface Water Technical Memorandum No. 92.10). 
The responsibility for ensuring that indirect measurements are performed correctly is that of the HSS chief. A review by the HSS chief of procedures and documentation is required before the measurement is considered final. It is a Northeastern Region Policy that each indirect measurement be sent to the Regional Surface-Water Specialist for review. If deficiencies are found during the review, actions taken to remedy the situation include written comments provided by the reviewer to the HSS chief. Measurements that are questionable and difficult to assess are reviewed by specialists outside the KWSC, and the HSS chief is responsible for ensuring that deficiencies identified by outside parties are corrected.

Determining when and where indirect measurements are made is the responsibility of the HSS chief. For the KWSC, it is a general rule that indirect measurements are made when the peak flow at a site is estimated to be more than two times the discharge of the greatest measured flow or when the upper end of the stage-discharge relation (rating curve) is poorly defined and it can be improved.

It is the responsibility of experienced hydrographers and field office chiefs to identify and flag high-water marks. Personnel traveling in the field are required to carry nails, plastic markers, spray paint, paint sticks, and survey flagging in their field vehicles, because the best quality and clarity of high-water marks is soon after a flood. The stream reach for indirect measurements at specified ranges of stage has been pre-selected at some streamflow-gaging-station sites and that information has been included in the station description, because selection of a suitable reach of channel is an extremely important element in making an indirect measurement.

After each indirect measurement is computed, the graphs, field notes and data, plotted profiles, maps, calculations or computer output, and written analysis associated with the measurement are checked by a qualified hydrographer assigned by the field office chief or the HSS chief. The information is organized in a single labeled folder and is then filed in the cabinet designated as the indirect measurement file. Long-term storage of each indirect-measurement package includes all computations and graphs and results in a single file, which is maintained in the KWSC.

\section{Peak Files}

The responsibility of maintaining the accuracy of the peak-flow data files, including computer database files, lies within the KWSC (Office of Surface Water Technical Memorandum No. 92.10). It is the responsibility of the Louisville field office chief to ensure that appropriate indirect-measurement results are entered into the peak-flow files, and it is the responsibility of the HSS chief to ensure that the peak-flow files are correct. For further discussion on the update and review of peak-flow files, refer to the "Database Management" section in this QA Plan.

\section{Crest-Stage Gages}

CSGs are used as tools throughout the USGS for determining peak stages at otherwise ungaged sites, confirming peak stages at selected sites where recording gages are located, confirming peak stages where pressure transducers are used, and determining peak stages along selected stream reaches or other locations, such as upstream and downstream from bridges and culverts. The OSW requires quality-assurance procedures comparable to those used at continuous-record stations for the operation of CSGs and for the computation of annual peaks at CSGs (Office of Surface Water Technical Memorandum No. 88.07).

The operation of five stand-alone CSGs is part of the KWSC surface-water program. CSGs are used at recording gages to confirm peaks. Procedures followed by the KWSC in the operation of CSGs are presented in Rantz and others (1982, p. 9, 77, and 78). One or more CSGs are maintained at each selected site where peak water-surface elevations are required on a stream.

Stage-discharge relations are developed in association with the gage based on direct high-water measurements except at sites where CSGs are used only to confirm or determine peak stages. Direct measurements are obtained, when appropriate, to verify or adjust the rating. Levels are run to the gage every 3 years or as soon as possible after appreciable changes in the gage, because of damage to the gage, reconstruction, or other such situation. When extremely high peaks occur, multiple outside high-water marks are located to confirm the gage readings, They are described on the note sheet and are flagged by a durable indicator so that the elevation of the high-water mark can be determined the next time levels are run.

Field observations are written on the CSG inspection note sheet. All field notes are required to include, at minimum, initials and last name of each field-crew member, date, time of observation, and the crest-stage reading.

The responsibility for ensuring that correct data-collection procedures are used by personnel is that of the field office chief. This responsibility is carried out by examining all field note sheets. When a deficiency in data-collection activities is identified, the problem is remedied by oral communication between the hydrographer and the field office chief.

Policies and procedures for computation of peak discharges at CSGs and associated documentation are presented in this report in the section titled "Processing and Analysis of Stage and Streamflow Data."

\section{Artificial Controls}

Artificial controls, including broad-crested weirs, thin-plate weirs, and flumes, are built in stream channels for simplifying the procedure of obtaining accurate records of discharge (Rantz and others, 1982, p. 12). Such structures serve to stabilize and constrict the channel at a section, reducing the variability of the stage-discharge relation. 
Artificial controls are used at some gaging stations maintained by the KWSC. In situations where artificial controls are installed as permanent structures, it is KWSC policy that stage-discharge relations are determined by making currentmeter measurements throughout the range of stage, if possible. If direct methods are not possible, theoretical methods are used and verified by some means of direct measurement. KWSC personnel use portable weir plates and flumes when it will increase the accuracy of the data collected. These portable devices are applied according to methods described in Buchanan and Somers (1969, p. 57) and Rantz and others (1982, p. 263).

Ensuring the correct design and installation of artificial controls for the KWSC is the responsibility of the field office chief. When installing an artificial control, the KWSC personnel take into account the criteria for selecting the various types of controls, principles governing their design, and the attributes considered desirable in such structures (Carter and Davidian, 1968, p. 3; Rantz and others, 1982, p. 15 and 348; and Kilpatrick and Schneider, 1983, p. 2 and 44).

Specific information pertaining to control conditions is written on the field note sheets when field inspections of artificial controls are performed to assist in analysis of the surfacewater data. These notes include information on the condition of the control structure, scour or fill of the streambed immediately upstream of the control, vegetative growth, and debris on the control. Regular maintenance at artificial controls includes cleaning the control and approach section during each site visit as needed and shooting the top of the structure when running levels. When field personnel encounter problems pertaining to artificial controls, field notes are made to document the problem. The problems are corrected immediately, if possible. If a control needs to be cleaned or repaired, gage readings are taken before and after any repairs or cleaning are attempted. If the site is to be measured, the measurement should be collected before any work or cleaning of the control occurs. If the problem is too large or severe to address at the current time, the field office chief or the HSS chief is notified so that necessary corrective actions can be scheduled.

\section{Flood Conditions}

Flood conditions present problems that do not occur on a regular basis. These problems include difficulties in gaining access to a streamflow gage or measuring site because roads and bridges are flooded, closed, or destroyed. Debris in the stream can damage equipment and present dangers to personnel collecting the data. Rapidly changing stage or conditions requiring measurements to be made at locations some distance away from the gage can create problems in associating a gage height to a measured discharge.

The KWSC maintains a flood plan so that high-priority surface-water data associated with flood conditions are collected properly and in a timely manner. The flood plan describes responsibilities before, during, and after a flood; informational-reporting procedures; and field-activity priorities. The flood plan serves as a central reference for emergency communications, telephone numbers for key KWSC personnel, and codes for accessing streamflow gages equipped with telemetry.

The HSS chief is responsible for ensuring that the flood plan includes all appropriate information and updates. The HSS chief reviews the flood plan and ensures a copy is provided to all field personnel in the HSS and other individuals in the KWSC who might assist in surface-water activities. Field personnel who receive a copy of the plan keep it in their field vehicle. The field office chiefs are responsible for ensuring that individuals who receive a copy of the flood plan are fully conversant with its content.

During local flooding, the HSS chief and the field office chief for that area coordinate flood activities. During larger floods, the HSS chief coordinates flood activities. The first responsibility of personnel that are not already in the field during flood conditions is to contact the HSS chief regarding assignments. The first responsibility of personnel already in the field during flood conditions is to contact the HSS chief at the beginning and end of each workday to provide streamflow information and updates on local conditions. Personnel who arrive at a gaging station to find that a flood has occurred are responsible for inspecting the site and the stage sensing equipment to establish a time and peak stage for that event; this may include locating HWMs if necessary. Field personnel are expected to use their knowledge, skills, and judgment (including safety) to prioritize their efforts when collecting the hydrologic data during flood conditions. Timely communication between themselves and the KWSC (HSS chief) is critical for the efficient use of their time during a flood. KWSC personnel apply methods discussed in Rantz and others (1982, p. 60) for determining peak stage at gaging stations.

KWSC personnel follow policies and procedures stated in a number of publications and memorandums when collecting surface-water data during floods. Techniques for current-meter measurements of flood flow are presented in Rantz and others (1982, p. 159-170). Procedures for identifying high-water marks for indirect discharge measurements are presented in Benson and Dalrymple (1967, p. 11). Adjustments applied to make measured flow hydraulically comparable with recorded gage height when discharge measurements are made a distance from the gaging station are presented in Office of Surface Water Technical Memorandum No. 92.09 and in Buchanan and Somers (1969, p. 54). It is the responsibility of all personnel with questions about particular policies or procedures related to flood activities, or who recognize their need for further training in any aspect of flood-data collection, to address their questions to the HSS chief.

Review of the KWSC activities related to floods is the responsibility of the KWSC Director. This review includes ensuring guidelines and priorities spelled out in the flood plan are followed and that the guidelines appropriately address KWSC requirements for obtaining flood data in a safe and thorough manner. When deficiencies are identified by the 
reviewer, deficiencies are remedied by oral communication to the KWSC Assistant Director. When appropriate, written memorandums from the KWSC Director concerning goals and policies are issued to all KWSC personnel. This improves the communication of those goals and policies within the KWSC.

\section{Low-Flow Conditions}

Streamflow conditions encountered by KWSC personnel during periods of low flow are typically quite different from those encountered during periods of medium and high flow. Low-flow discharge measurements are made to define or confirm the lower portions of stage-discharge relations for gaging stations, as part of seepage runs to identify channel gains or losses, and to help in the interpretation of other associated data. Additionally, low-flow measurements are made to define the relation between low-flow characteristics in one basin and those of a nearby basin for which more data are available (Office of Surface Water Technical Memorandum No. 85.17).

In many situations, low flows are associated with factors that reduce the accuracy of discharge measurements. These factors include algae growth that impedes the free movement of current-meter buckets and larger percentages of the flow moving in the narrow spaces between cobbles. When natural conditions are in the range considered by field personnel to be undependable, the cross section is physically improved for measurement by removal of debris or large cobbles, construction of dikes to reduce the amount of non-flowing water, or other such efforts (Buchanan and Somers, 1969, p. 39). After modification of the cross section, the flow is allowed to stabilize before the discharge measurement is initiated. The control for the measurement section is never modified for improving the measurement. If the control or channel modifications affect the stage at the gage, stage readings and times are documented on the discharge measurement sheet so that the appropriate datum or shift can be applied at that time.

KWSC policy requires that point-of-zero-flow (PZF) measurements are made by field personnel during periods of low flow at all gages where the low-flow control is recognizable and the stream is wadeable. Gage height of zero flow is determined by measuring the depth of water at the lowest point of the section control; this is referenced to the measurement gage height and datum.

The appropriate field office chief is responsible for ensuring that KWSC personnel use appropriate equipment and procedures during periods of low flow. The field office chief determines that appropriate procedures were used for data-collection activities during low-flow conditions by reviewing all field notes after the field trip has been completed and by the hydrographer that is working that station's streamflow records. The HSS chief or appropriate field office chief is responsible for providing answers to questions from KWSC personnel pertaining to data collection during periods of low flow.

\section{Cold-Weather Conditions}

Surface-water activities in the KWSC include making streamflow-discharge measurements during cold-weather conditions. Cold temperatures, wind, snow, and ice can create difficulties in collecting data; these factors also can create dangers to field personnel. Employee safety is the highest priority in collecting streamflow data during winter periods.

Discharge measurements under ice cover and during periods of partial ice cover are useful for analysis and determination of flow throughout winter periods for gaging stations where the stream is subject to freezing. KWSC personnel are required to follow procedures for discharge measurements under ice cover presented in Buchanan and Somers (1969, p. 42). This same publication includes procedures for discharge measurements made by wading or discharge measurements from cableways and bridges when debris and ice are in the streamflow. KWSC personnel also follow procedures to collect winter streamflow data as presented in Rantz and others (1982, p. 124). Additionally, guidelines on equipment for measurement of flow under ice are provided in Office of Surface Water Technical Memorandum No. 84.05.

Presently (2006), OSW views the preferred metering equipment for discharge measurements for slush-free conditions under ice cover to be a type AA current meter built with a Water Survey of Canada winter-style yoke and a conventional metal-cup rotor. For conditions where slush ice is present, the OSW views the preferred metering equipment to be the Water Survey of Canada winter-style yoke with a polymer rotor (Office of Surface Water Technical Memorandum No. 88.18). Although polymer rotors are not allowed (Office of Surface Water Technical Memorandum No. 90.01) during all other conditions, the superior ability of the polymer rotor to shed slush ice and retard freezing in ice-covered streams is considered to be more important than the turbulentflow-related inaccuracies associated with the rotor (Office of Surface Water Technical Memorandum No. 92.04). The OSW also views the regular AA meters with conventional metalbucket rotors to be acceptable for use in slush-free conditions if cutting the required larger holes through the ice is feasible (Office of Surface Water Technical Memorandum No. 92.04).

The KWSC uses Price AA meters and Flowtrackers to make measurements when the conditions allow the hydrographer to wade the stream and Price AA and ADCPs when the stream is above wadeable conditions. When the effective depth of water under ice cover is less than $1.5 \mathrm{ft}$, a pygmy meter is used.

The HSS chief or field office chiefs are responsible for ensuring the correct use of equipment and procedures for surface-water data-collection activities during winter conditions. This is accomplished by the same procedures as documented for warm-weather conditions. 


\section{Processing and Analysis of Streamflow Data}

The computation of streamflow records involves the analysis of field observations and field measurements, the determination of stage-discharge relations, adjustment and application of those relations, and systematic documentation of the methods and decisions that were applied. Streamflow records are computed and published annually for each gaging station (Rantz and others, 1982, p. 544).

This section of the QA Plan includes descriptions of procedures and policies pertaining to the processing and analysis of data associated with the computation of streamflow data, including real-time streamflow data. The procedures followed by the KWSC coincide with those described in Rantz and others (1982) and in Kennedy (1983).

\section{Processing of Real-Time Streamflow Data}

A necessary and critical element in maintaining accurate streamflow records on a real-time basis is the need for rating analysis, gage-height correction, and shift application as soon as practicable after a streamflow measurement has been made. KWSC policy is that rating analyses and shift applications will be performed using the following procedures for data disseminated on the KWSC public webpage http://ky.water.usgs.gov.

It is KWSC policy that real-time data presented on the KWSC web pages are considered provisional and subject to revision. Website users are warned of the inherent limitations of the provisional data and have the opportunity to view what the term "provisional data" means by clicking on the explanation. The real-time data are inspected for errors and transmission inventory every day by experienced hydrographers or the field office chiefs. The KWSC uses the "screening thresholds" that ADAPS provides to help with the QA/QC of the realtime data. The KWSC is attempting to keep records worked current so that needed shifts and data corrections are applied in a timely manner to the data that is available on the Internet. ALL KWSC streamflow stations are equipped with telemetry. The field office chief and the hydrographer (after returning from the field) are responsible for ensuring every effort is made to update station information with the correct shift and data corrections in a timely manner.

During high-water periods and major flooding, the realtime data are an integral part of improving and maintaining the upper end of the stage-discharge rating curve. The realtime data from the USGS and the projected crests from the National Weather Service (NWS) are used to determine which stations become priorities and what time personnel should be deployed. The KWSC is updating many of its stations with high-data-rate (HDR) telemetry. This gives the USGS, NWS, and the public hourly access to the data. It is the responsibility of the field personnel to call the KWSC and report measurement data to the HSS chief or the field office chief. These flood measurements are used to update station ratings, shifts, and other aspects of the real-time streamflow computations. Priorities for measurements at gaging stations and CSG sites are listed in the KWSC Flood Plan. Questions about priorities should be directed to the HSS chief or the field office chiefs.

\section{Webpage Presentation Format}

Kentucky real-time data are served from computers located in the Louisville office and maintained by the KWSC. The National Water Information System (NWIS) software is used to conform to national USGS standards. Links to real-time streamflow data are displayed on the KWSC home page under "Real-time Data for Kentucky." Through this link, access to a default table of all Kentucky surface-water stations is available. The KWSC Director has the ultimate responsibility of approving all content that is posted on the KWSC website.

\section{Review of Real-Time Streamflow Data}

Real-time streamflow data disseminated on the public webpage must be reviewed frequently to ensure their quality and prevent the distribution of erroneous information. The KWSC uses both automated and manual review procedures to meet this objective.

Automated procedures implemented by the KWSC include the setting of minimum and maximum threshold values for stage and discharge and their rates of change. If exceeded, these settings will initiate warnings of potential errors that will be delivered by e-mail to the appropriate KWSC personnel. The field office chiefs and the HSS chief are designated to receive and act upon these messages.

In addition to the automated procedures, Water Resources Division Memorandum No. 97.17 requires frequent and ongoing screening and review of web data, including at least daily review of hydrographs during normal hours of operation. The KWSC requires that all web pages containing real-time streamflow data be reviewed regularly for accuracy and (or) missing data. The real-time stage and streamflow data are viewed each morning by experienced hydrographers or the field office chiefs. The primary goal is to identify stations that have failed to transmit the real-time data or to identify any problems that station may be experiencing by scanning the data itself. When problems are identified, the field office chiefs or the HSS chief initiates necessary corrective actions. Another goal is to view the data for situations in which special measurements are needed, such as high water, backwater, or low flows, that will improve the records working process and provide additional information for the streamflow network. 


\section{Error Handling}

There are two general types of errors associated with streamflow data that are delivered by the real-time system and disseminated on the Internet. The first is persistent-type problems usually associated with some type of equipment failure whether in data collection or transmission, but could also be related to other effects. They occur on a continuing basis for more than a single recording interval because of the nature of the problem. The second is the intermittent-type problems, which are often the result of a data-transmission error. These often show up as either a zero or an unreasonably large value. When these errors occur, it is KWSC policy that they are corrected as soon as possible as other work priorities allow. The KWSC attempts to get all problems resolved within 24 to 48 hours (during the work week) of identifying the problem. The field office chief in consultation with the HSS chief is responsible for deciding when data are removed from the webpage; posting of real-time data on the Internet is resumed after repairs are made.

\section{Data-Qualification Statements}

Water Resources Division Memorandum No. 95.19 requires that streamflow data made available on the Internet be considered provisional until the formal review process has been completed. Data qualification statements must be included at key locations with a clickable heading "Provisional Data Subject to Revision" on all real-time data pages to ensure that everyone who accesses data from the Internet is aware of this.

\section{Measurements and Field Notes}

Gage-height information, discharge information, control conditions, and other field observations written by personnel onto the measurement note sheets and other field note sheets form the basis for records computation for each gaging station. Measurements and field notes that contain original data are required to be stored indefinitely (Hubbard, 1992).

Measurements and other field notes for the water year that is currently being computed are filed in the current water year filing cabinets; each file is labeled by its station number. Measurements and notes for previous water years are back filed in each field office.

KWSC policy is that all streamflow measurements are checked. All conventional and Flowtracker measurements are checked by a HSS member, and all ADCP measurements are checked by someone that has completed the USGS Hydroacoustics training. The measurements are checked by reviewing the mathematics and other items listed in Kennedy (1983, p. 7).

\section{Continuous Record}

Surface-water gage-height data are collected as continuous record (60-, 30-, 15-, or 5-minute values) in the form of electronic transmissions by satellite or telephone and their back-up electronic data files. Streamflow records are computed by converting gage-height record to discharge record through application of stage-discharge relations. Ensuring the accuracy of gage-height record is, therefore, a necessary component of ensuring the accuracy of computed discharges.

Gage-height record is assembled for the period of analysis in as complete a manner as possible. Periods of inaccurate gage-height data are identified then corrected (see the section "Datum corrections, gage-height corrections, and shifts") or deleted. Items included in the assembly of gage-height record and procedures for processing the data are discussed in Kennedy (1983, p. 6) and Rantz and others (1982, p. 560 and 587).

All surface-water data transmitted by satellite or phone are automatically entered into ADAPS through DECODES. All surface-water data stored or backed up on a compact flash card are manually transferred and entered into ADAPS through DECODES. Since the KWSC surface-water data network is 100 percent telemetered, most of the data brought in from the field is back-up data. Copies of the "raw data" are archived in the "raw_data" directory on the UNIX computer system; the "raw data" files are maintained unaltered for future reference. The hydrographer is responsible for loading the back-up data into the primary data-descriptor to ensure that if there are gaps in the primary data set, he/she will have access to the back-up data. The hydrographer should review all stage data by using the graphical routines (HYDRA) within ADAPS.

\section{Records and Computation}

Each field office is responsible for maintaining their surface-water station files. These files are located in an easily accessible area and are clearly labeled by their station number or station name. The responsibility for working continuous records for each station is assigned by each field office chief to a specific hydrographer each year. It is the goal of the KWSC that records are assigned to the same individual who operates and maintains the field station. Only part of the records are assigned to the gaging station operator because of the number of stations and the amount of other project work he/she is assigned. Records computation is done on a continuing basis to improve the accuracy of the real-time data. The responsibility of checking and reviewing the continuous records is assigned to other hydrographers from within the same field office, another field office, or another Water Science Center. The Kentucky, Indiana, and Ohio Water Science Centers check and review records for each other each year on a rotational basis. 


\section{Procedures for Working and Checking Records}

Procedures for ensuring the thoroughness, consistency, and accuracy of streamflow records are described in this section of the QA Plan. The KWSC has a records computation checklist for each station that is used to track the steps completed in the computation process. The goals, procedures, and policies presented in this section are grouped in association with the separate components that are included in the recordscomputation process.

\section{Gage Height}

The accuracy of surface-water discharge records depends upon the accuracy of discharge measurements, accuracy of rating definition, and the completeness and accuracy of the gageheight record (Office of Surface Water Technical Memorandum No. 93.07). Computation of streamflow records includes ensuring the accuracy of gage-height record by comparisons of gage-height readings made by use of independent reference gages, comparison of inside and outside gages, examination of high-water marks, comparisons of the redundant recordings of peaks and troughs by use of maximum and minimum indicators, examination of data obtained at CSGs, and confirmation or updating of gage datums by levels.

Records computation includes examination of gageheight record to determine if the record accurately represents the stage of the body of water being monitored. Additionally, it includes identifying periods during which inaccuracies have occurred and determining the cause for those inaccuracies. When possible and appropriate, inaccurate gage-height record is corrected. When corrections are not possible, the erroneous gage-height data are removed from the set of data used for streamflow records computation. The missing data are documented in the Station Analysis as to the reason why they are missing.

Gage height or stage data that accurately reflect the stream level are kept. Any data that do not follow that statement are reviewed and then removed from the working database. A copy of all raw data is kept within the NWIS database. Each station has a primary data set, which are data that are transmitted via satellite and a back-up data set, which are the data retrieved manually from the field. In the case of bad or missing primary record, if the back-up gage height is available and correct, it should be used. The back-up data should be copied to the primary data descriptor and noted in the station analysis. The hydrographer computing the record is responsible for ensuring that the final record contains all the corrections needed, and assigned checkers verify that the correct procedures were followed.

\section{Levels}

Errors in gage-height data caused by vertical changes in the gage or gage-supporting structure can be measured by running levels. Gages can be reset or gage readings can be adjusted by applying corrections based on levels (Kennedy, 1983, p. 6).

Procedures for computing records for each station include adjusting the gage-height values based on the current level data. Other procedures include ensuring that the front sheet has been completed for each set of levels, checking the level notes for mistakes, ensuring that the level information is listed correctly in the historical level summary, and ensuring that datum corrections were applied appropriately. The individual computing the record is required to check field notes for indications that the gages were reset correctly. If the gages were not reset correctly, the hydrographer computing the record should inform the field office chief and the field personnel responsible for the mistake so that corrective actions can be taken. The individual computing the records makes appropriate adjustments to the gage-height record by applying data corrections. All changes are noted in the station analysis and station description.

\section{Rating}

The development of the stage-discharge relation, also called the rating, is one of the principal tasks in computing discharge record. The rating is usually the relation between gage height and discharge (simple rating). Ratings for some special sites involve additional factors such as rate of change in stage or fall in slope reach (complex ratings) (Kennedy, 1983, p. 14).

KWSC personnel follow procedures for the development, modification, and application of ratings that are described in Kennedy (1984). KWSC personnel follow guidelines pertaining to rating and records computation that are presented in Kennedy (1983, p. 14) and in Rantz and others (1982, chap. 10-14 and p. 549).

For each gaging station, the most recent digital rating table or graphical rating curve can be obtained by producing a printout from ADAPS. A current paper copy of each is kept in the station file for the current water year. A copy of the most recent rating table and curve is kept at each gaging station. All old rating tables and curves are kept in the back files. New discharge rating curves developed by the hydrographer computing the record are considered "working" ratings until either the field office chief or the HSS chief approves them. Once approved, the field office chief or HSS chief must change the "working" flag to an "approved" flag so that the conversion of stage to discharge will be allowed when running a primary computation in ADAPS.

\section{Datum Corrections, Gage-Height Corrections, and Shifts}

A correction applied to gage-height readings to compensate for the effect of settlement or uplift of the gage is usually measured by levels and is called a "datum correction" (Kennedy, 1983, p. 9). Datum corrections are applied to gage-height record in terms of magnitude (in feet) and in terms of when the datum change occurred. In the absence of any evidence indicating exactly when the change occurred, the change is assumed to have occurred gradually from the time 
the previous levels were run, and the correction is prorated with time (Rantz and others, 1982, p. 545). Datum corrections are applied when the magnitude of the vertical change is greater than $0.015 \mathrm{ft}$.

A correction applied to gage-height readings to compensate for differences between the recording gage and the base gage is called a "gage-height correction" (Rantz and others, 1982, p. 563). These corrections are applied in the same manner as datum corrections by use of the same computer software. Gage-height corrections are applied so the recorded data are made to agree with base-gage data. These corrections are applied when the difference between the recording gage and the base gage is equal to or greater than $0.02 \mathrm{ft}$. Corrections should be made at discrepancies of $.01 \mathrm{ft}$ if the effect of the change in stage creates a greater-than 5-percent change in discharge.

A shift is a correction applied to the stage-discharge relation, or rating, to compensate for variations in the rating. Shifts indicate that stage-discharge relations are not permanent but vary from time to time, either gradually or abruptly, because of changes in the physical features that form the control at the gaging station (Rantz and others, 1982, p. 344). Shifts can be applied to vary in magnitude with time and with stage (Kennedy, 1983, p. 35). The KWSC uses the "variablestage shift" philosophy to make temporary changes to the rating based on the most recent "in-stream" measurement and the stage associated with it. Different shifts are applied to field measurements based on their quality rating. A measurement rated "GOOD" allows the discharge to plot within 5 percent of the rating without requiring a shift. A measurement of "FAIR" allows the discharge to plot within 8 percent of the rating without requiring a shift. Any measurement rated "POOR" (greater than 8 percent from the rating) should be looked at individually to determine how much shift is needed or if the measurement will be used at all for the shifting analysis. Shifts are documented by magnitude and time. They are described in the station analysis using a shift paragraph, which is a narrative that describes how shifts-by-stage were distributed, and entered into the measurement summary file. The shift-diagram points are plotted on the working rating so the hydraulic logic of the shift curve can be seen.

Datum corrections, gage-height corrections, and shifts for each station are entered into the standard USGS data-processing software (ADAPS) and are stored as finalized data upon completion of the KWSC's records-working process. The hydrographer who works the station records ensures that recorded gage heights and computed streamflows represent a logical and smooth transition between water years; the checker and reviewer verify this process. Datum corrections, gageheight corrections, and shifts are documented in the station analysis, and associated graphs and computer printouts are attached to the station analysis as part of the permanent record. This documentation is maintained indefinitely for future reference.

\section{Hydrographs}

A discharge hydrograph is a plot of daily mean discharges versus time. The date is aligned with the horizontal axis, and the discharge is aligned with the logarithmic vertical axis. In the process of computing station records, this hydrograph is a useful tool in identifying periods of erroneous information, such as incorrect shifts or datum corrections. Additionally, hydrographs are helpful when estimating discharges for periods of undefined stage-discharge relation, such as during backwater or ice conditions, and in estimating discharges for periods of missing record.

The following information, at a minimum, is placed on the hydrograph for each station: station name, station number, water year, date the hydrograph was plotted, drainage area, plot of daily mean discharge data, plots of measurements, indications of datum corrections and shifts, streamflow stations with which the hydrograph was compared, periods of missing record, periods of ice effect, estimated discharges for missing record, and the maximum instantaneous discharge for the water year. All hydrographs are plotted using the standard format with five cycles, which allows comparison of one station to another.

Hydrographic comparison with one station to those of nearby stations is an effective means to evaluate the validity of shift, datum, or gage-height correction applications. It can be used to identify periods of faulty gage-height data and estimating discharges for periods of missing record or periods of no stage-discharge relation. Hydrographic comparisons, as described in Rantz and others (1982, p. 575), is a component of records computation for each streamflow-gaging station in Kentucky. Hydrographs for the current year are maintained in separate filing drawers and labeled by their station name. After records are computed, checked, and reviewed, each hydrograph is filed in a station folder, backfiled, and maintained for future reference.

\section{Station Analysis}

A complete analysis of data collected, procedures used in processing the data, and the logic upon which the computations were based is documented for each year of record for each station to provide a basis for review and to serve as a reference for possible future questions (Rantz and others, 1982, p. 580). Topics discussed in detail in the station analysis may include equipment, hydrologic conditions, gage-height record, datum corrections, rating, discharge, ice-affected periods, special computations, remarks concerning data quality, recommendations, and hydrographic comparison. The station analysis is written by the hydrographer who works the streamflow records. All station analyses are written using Microsoft Word and stored in the "KYPROJ" directory on the UNIX server. A hard copy is kept in the current water year station file. Station analyses from previous years are backfiled and kept in separate folders based on water year and station number. An electronic copy is stored and backed up on the UNIX server. It is the responsibility of the hydrographer working the record 
to ensure that the computation process is comprehensive and complete and that all aspects of the process are documented fully in the station analysis and associated material. The checker and reviewer responsibilities are to ensure that all aspects of the records-computation process for the station were carried out correctly and completely and that the documentation is clear, complete, and accurate. If a difference of opinion arises between the preparer of the record and the checker, the difference is resolved by the field office chief or the HSS chief. The field office chiefs are responsible for ensuring that the station analyses are prepared properly and filed correctly.

\section{Winter Records}

Computing gaging-station records for winter periods involves different procedures than those that are used other times of the year. The formation of ice in stream channels or on section controls affects the stage-discharge relation by causing backwater; the effect varies with the quantity and nature of the ice, as well as with the discharge (Rantz and others, 1982, p. 360). During some conditions, the recorded gage-height data may be accurate, although the actual stagedischarge relation may be undeterminable and unstable. An example of this condition is when surface ice forms on the stream, but the stilling well remains unfrozen and the water level in the stilling well represents the backpressure caused by the ice in the channel. During other conditions, the recorded gage-height data are inaccurate, resulting in periods of missing gage-height record. An example of the latter would be a stilling well or the intakes to the stilling well are frozen.

The individual computing the station record is responsible for identifying ice-affected periods and documenting the periods in the station analysis and on the hydrograph. The individual estimates daily mean discharges for the period, identifies periods of faulty or missing gage-height record, and enters the estimated discharge into the daily-values computer file. The individual who checks the winter records is responsible for confirming that the determinations of ice-affected periods, the estimates of daily discharge, and the data entered into the daily-values computer file are correct. If the checker agrees with the periods of faulty gage-height record, they are responsible for deleting the faulty unit-value data or marking the data erroneous from the unit-values computer file. If the checker disagrees, the field office chief or the HSS chief will make the final determination.

In general, the checker is responsible for making corrections to data files and documentation; however, the original worker is responsible for broad-scale changes.

Hydrographers who work station records for winter periods use a combination of recorded gage-height data, precipitation and temperature data, and other environmental information that may be available. Although ice-affected discharge measurements are representative only for a specific site at a specific time, those measurements are helpful for determining a general range of discharge for estimating daily means for a selected period for certain nearby gaging stations.
Unit-value plots are used for identifying streamflow patterns associated with the occurrence of ice. Hydrographic comparison, using the daily value hydrographs, with nearby gaging stations is useful in estimating daily mean discharges. Nearby gaging stations are useful, particularly in hydrographic comparison for winter periods when those stations tend to remain unfrozen because of large amounts of ground water entering the flow system, heat from power plants or similar facilities entering the flow system, or warmer outflows being released from reservoirs. Records from nearby gaging stations are useful if the discharges are computed by an acoustical gage and are considered poor for days that discharges are determined by estimation.

\section{Unit-Value and Daily-Value Estimates}

In general, unit-value gage height should not be estimated unless there is a high degree of confidence that little or no loss of accuracy will result from the estimation, and the period to be estimated is less than 12 hours. In this case, the resultant daily mean discharge computed from this record is not labeled "estimated." Daily mean discharges may be estimated in the same manner that estimated record has been done traditionally. The hydrographer estimating the daily mean discharge must plot the original daily mean values from the primary record printout onto the hydrograph so that the checker and reviewer can see the original rating-produced discharge along with the estimated discharge.

\section{Hydra and MISTE}

Hydra and MISTE are new powerful tools in ADAPS that can be used to expedite record estimation. Hydra allows the data to be presented in graphical and tabular forms and can be used to modify or delete unit and daily values. MISTE resides inside Hydra and can be used to create regression-curve estimates of daily discharges. MISTE is useful when the original data are missing, and an estimate must be made. Data created by MISTE can be loaded into Hydra as a reference curve; data from the reference curve can be copied into the original data set and used to fill in the missing gaps. The data values automatically are flagged as estimated data. If used correctly, these programs are a time saver in estimating data.

\section{Furnished Records}

Surface-water data collected under the supervision of other agencies, organizations, or institutions are received by this office. These data are used for publication in the annual data report. Gate-opening, turbine, and lockage data from USACE high-lift dams on the Ohio River are provided to the KWSC and used to compute flow at these high-lift dams. The daily streamflows are published in the annual data report, and the agency that furnished the data is identified. 


\section{Daily-Values Table}

A discharge value is determined and stored for each day for each gaging station operated by the USGS, with few exceptions. The daily values table generated by use of the records-computation software represents what discharge values are stored for each day of the water year.

At present, daily mean discharges are the major product of the records-computation process. It is the responsibility of the hydrographer working the records to verify the accuracy of the daily mean discharges and to use the daily values table to cross check values written on primaries or plotted on the hydrograph. The hydrographer ensures that proper daily mean discharge values have been stored; the daily values table is used to check the final manuscript before the data are published. Paper copies of the daily values table are stored for future reference in the current year station files and the backfiles for each station. The field office chiefs are responsible for properly back filing all information pertinent to the station file in a given year. Daily values tables that have been finalized are initialed by the checker or reviewer before being added to the manuscript.

\section{Manuscript and Annual Water-Data Report}

When records computation for the water year is complete and the data collected and analyzed by KWSC personnel have been determined to be correct and finalized, the surface-water data for that water year are published along with other data in the KWSC annual data report. The annual data report is part of the series titled "U.S. Geological Survey Water-Data Reports." Information presented in the annual data report includes daily discharge values during the year, extremes for the year and period of record, and various statistics. Additionally, manuscript station descriptions are presented in the annual data report. Information contained in the manuscript includes physical descriptions of the gage and basin, history of the station and data, and statements of cooperation. Manuscripts for publication in the annual data report are produced using scripts, which were created by USGS personnel. Using these scripts, the final daily mean discharge table, including final streamflow statistics, is loaded directly into the manuscript files. Potential data-transfer errors are minimized by use of these automated scripts. Finally, the lead author and the HSS chief review the entire report. In preparing the annual waterdata report for publication, the KWSC follows the guidelines presented in the report titled, "WRD Data Reports Preparation Guide," by Charles E. Novak, 1985 edition and Office of Water Information Technical Memorandum No. 2003.02, "Guidelines for the Release of the Annual State Water Data Reports," January 2003.

\section{Kentucky Water Science Center Checklist}

The status of progress on records computation for each gaging station in Kentucky is posted in each field office on a single highly visible white board. Each white board contains a gaging-station list based on the respective field office area. Each gaging-station name is followed by a series of blanks; the blanks are for the hydrographer's initials to indicate the work, check, and review completion rate based on annual quarters. The KWSC uses a gaging-station records-computation checklist to track the status of records computations for each station and to ensure that errors do not occur by omitting the necessary procedural steps. The checklist is designed to step a person through the process of working and checking a record; there is a separate checklist for the reviewer. After the station is completed, the checklists are backfiled with the rest of the station information that is not needed in the next water year. During the water year, monthly status reports are sent to the Northeastern Region Surface-Water Specialists.

\section{Review of Records}

After streamflow records for each station have been computed and checked, records for the majority of the KWSC's gaging stations are reviewed by experienced hydrographers, field office chiefs, and senior hydrographers from other Water Science Centers. The goal of the review is to ensure that proper methods were applied throughout the process of obtaining the surface-water data and computing the records. Kentucky, Indiana, Ohio, and occasionally West Virginia Water Science Centers participate in a rotational trip each year that allows each Water Science Center to check and review a substantial amount of records for each other. The results of the rotational review are shared with the Water Science Centers hydrographers in a wrap-up session at the end of the week. The comments are put in writing and given to each Data Section chief to keep as reference and training tools for future records computations. The goal of the KWSC is to publish a product that is as free of errors as is humanly possible while being fiscally responsible. The HSS chief is responsible for ensuring that any deficiencies identified in the review are corrected and that actions are taken to prevent their recurrence.

\section{Crest-Stage Gages}

Records for CSGs are computed with goals and procedures similar to those for other gaging stations. The field notes are examined for correctness and accuracy. Peak stages recorded by CSGs are cross referenced with other available information; the dates of the peaks are determined by analyzing available precipitation data and peak data from recording gages within the same basin or from nearby basins.

A discussion on the policies and procedures used for field aspects of collecting data at CSGs is included in this report in the section "Collection of Stage and Streamflow Data." The discussion in this section describes the analysis and office documentation of crest-stage data. This section does not pertain to data collected at CSGs installed solely for confirming peak stages at sites where pressure-transducer gages are used. 
At sites where CSGs are used to compute peak discharges, an initial stage-discharge relation, or rating, is developed for the site by direct or indirect high-water measurements. The rating is verified or adjusted based on subsequent direct or indirect high-water measurements.

For each station, a list of all measurements is maintained and each measurement is assigned a chronological number. For each station, a graphical plot of the current rating along with each recent and each notably high stage-discharge measurement is made readily available to those who check and review the station record by pulling the information from ADAPS. Current station descriptions and a summary of levels are maintained in the station file. A brief station analysis is written each year describing computation of the annual peak, identifying which rating was used and the type of flow condition, describing how the dates of the peaks were determined, and explaining any shift that may have been applied. Computing peak discharges and updating the manuscripts for each CSG is the responsibility of the hydrographer assigned to the station.

The field office chief is responsible for assigning personnel for each CSG station. Computations are checked by another experienced hydrographer and reviewed by the field office chief.

The field office chief is responsible for ensuring the correct computation of annual peaks at CSGs. Review of the CSG computations is done by the field office chief. When incorrect actions or procedures are identified during the review, the problems are remedied by addressing the deficiencies with the hydrographer that computed the record and providing in-time training.

A hydrographer within the KWSC is responsible for updating the Peak-Flow File promptly after peak data have been finalized. A current listing of annual peaks is maintained in the station folder for review purposes (Office of Surface Water Technical Memorandum No. 88.07).

\section{Office Setting}

Maintaining surface-water data and related information in a systematic and organized manner increases the efficiency and effectiveness of data-analysis and data-dissemination efforts. Good organization of files reduces the likelihood of misplaced information; misplaced data and field notes can lead to analyses based on inadequate information, with a possible decrease in the quality of analytical results.

This section of the QA Plan includes descriptions of how station folders, reference maps, levels documentation, and other information related to surface-water data are organized and maintained. Additionally, this section provides an overview of how work activities are designed to be carried out within the office setting.

\section{Work Plan}

It is the responsibility of the three field office chiefs to assign duties associated with the collection, analysis, storage, and publication of surface-water data, unless the data are for a separate project. This includes the scheduling of field work and day-to-day office work. Stations are assigned to field offices or individuals and are grouped into field trips. Field trips are assigned to individual field personnel who are responsible for all site visits as well as reviewing the real-time data from those sites. KWSC hydrographers do more than collect basic data; they are involved in many projects within the HIS. The hydrographers assigned to the HSS are used by project chiefs from the HIS. The HSS chief, HIS chief and (or) project chiefs are responsible for resolving any scheduling conflicts involving the use of HSS hydrographers. Field office chiefs are responsible for ensuring that field personnel have the required office time needed to complete their surface-water records computations. Field personnel are responsible for using their office time wisely and efficiently to work on their surfacewater records. Each employee has a performance plan, which outlines their primary responsibilities and the criteria that are used to evaluate their performance.

\section{File Folders for Surface-Water Stations}

This section of the QA Plan describes the location and structure of hard-copy files associated with surface-water data. Information pertaining to files maintained in computer storage can be found in the "Database Management" section of this report.

For each gaging station, a separate set of file folders is maintained in a set of filing cabinets located in the HSS. Files are arranged by station number in chronological downstream order. Folders containing long-term information are grouped with folders containing current information. Each current folder includes station descriptions, station analyses, shift analysis, stage-shift diagrams, ratings, datum correction sheets, measurement summary, level summary, primary computation sheets, hydrographs, and checklists for tracking the work process. Extraneous items are removed from the current files after records for all gaging stations are determined by the HSS chief to be finalized for that water year. Backfile folders for previous water years are stored by station number and separated from current files. Field office chiefs are responsible for ensuring that appropriate documentation is filed correctly and unnecessary notes and work sheets are discarded.

The set of current files in each office for each station are grouped as follows:

Station Folders-The station folders contain primarycomputation printouts and working unit-value plots. They contain recent measurements, field notes, inspection sheets, in-progress station analysis, discharge rating table, station description, variable-shift diagrams, photos, level summary, shift and datum printouts, the Form 9-207 of the measurement 
list, and the checklist being used to track the work progress on the station.

Graphs of Ratings - The master graphs of ratings (rating curves) in current use are stored, unfolded, in a series of wide file drawers. The rating curves are filed by station name in alphabetical order. Once a rating curve is updated or changed, the previous version is backfiled. The current rating as well as the previous rating should be plotted on the master rating; a new trend is to plot the shift curves on the master rating. The KWSC has begun reviewing this approach, but not every station will have this feature.

Discharge Hydrographs - The discharge hydrograph represents the mean daily discharge in the water year for which the records are being worked. They are stored, unfolded, in a series of wide file drawers in alphabetical order by station name. After the records for the current year have been finalized, the hydrograph for each station is folded and placed in the station backfile folder.

The set of backfiles for each office is grouped for each station as follows:

Primary History Folders-The primary history folders contain the history of the gage. They contain all the information about the site including construction information, old photos and diagrams, cooperator correspondence, memorandums, old ratings, and daily-values tables prior to the establishment of Water-Year Folders.

Water-Year Folders - The water-year folders are a complete package of the information used to compute the final unit and daily values for that particular station. They are backfiled by station number and by water year. The folders may include primary computations, rating tables and curves, shift and datum worksheets, hydrographs, monthly unit value plots, and station analysis. The information in these folders will allow you to work up the surface-water data for that year.

Measurement Notes-Measurement notes are kept in labeled file drawers, grouped by station using the station number in downstream order. Each field office keeps their measurements indefinitely.

Station Levels-Backfiled station levels are kept in labeled file drawers, grouped by station using the station number in downstream order. Each field office keeps their station levels indefinitely.

\section{Field-Trip Folders}

Each hydrographer is responsible for maintaining field folders for their assigned field-trip area. The folders contain station descriptions, safety information, traffic control plans, job hazard analysis, station lists, rating and discharge measurement data, levels summaries, and other pertinent information for each site. Each group of stations in a field trip is kept in a field file along with the current flood plan and detailed road maps.

\section{Levels}

Level note sheets, with completed summary front sheet for the current year, are filed in the current primary folder. A summary of levels for each station is filed in the field folders. After records are finalized, the outdated level note sheets are backfiled in a series of labeled drawers within the HSS.

\section{Station Descriptions}

Copies of current surface-water station descriptions are maintained in the current station folders located in each KWSC office. The original descriptions are stored in electronic format, in the "KYPROJ" directory on the Unix Server. The station descriptions are created and updated using Microsoft Word. The hydrographer computing the surfacewater records is responsible for keeping the station description updated. The KWSC goal is to update station descriptions annually.

\section{Discontinued Stations}

Station descriptions, station analysis, stage-discharge ratings, lists of measurements, correspondence, and other documents associated with discontinued stations are maintained in specific, labeled cabinets located in each KWSC office. Folders are grouped by station number and arranged by water year.

\section{Map Files}

A set of 7.5-minute topographic maps representing coverage of the entire Commonwealth of Kentucky is maintained for identifying the location of all surface- and ground-water data-collection sites. Each observation site is plotted on the appropriate map. A second set of 7.5-minute topographic maps is maintained for delineating surface-drainage areas. No map from either set is allowed to be removed from the office unless permission is granted from the HSS chief. There are work maps available for field use, which are stored in wide file drawers within the KWSC. It is the responsibility of the HSS chief or the Louisville field office chief to ensure these map sets are updated when new stations are established. These maps may become an electronic database as the KWSC gets more involved with GIS.

\section{Archiving}

All KWSC personnel are directed to safeguard all original field records containing geologic and hydrogeologic measurements and observations. Selected material not maintained in field offices are placed in archival storage. Detailed information on what records have been removed to archival centers should be retained in the Water Science Center or project office (Water Resources Division Memorandum No. 77.83). 
The types of original data that should be archived include, but are not limited to, recorder charts and tapes, original data and edited data, observers' notes and readings, station descriptions, analyses, and other supporting information (Water Resources Division Memorandum No. 92.59 and Hubbard, 1992, p. 12). At this time, there is an agreement between the USGS and the Federal Records Centers (FRC) of the National Archives and Records Administration (NARA) to archive original-data records (memorandum from the Chief, Branch of Operational Support, May 7, 1993). The KWSC does NOT send surfacewater information to the FRC.

\section{Communication of New Methods and Current Procedures}

The content of all new policies issued through memorandums by the USGS or the OSW are emphasized or communicated by the HSS chief. Most memorandums are transmitted through e-mail to all employees. The HSS chief is responsible for ensuring that all HSS employees are made aware of new policies, either by additional e-mail or verbally at section meetings or "in-house" training sessions. The HSS chief is responsible for ensuring that KWSC personnel collecting surface-water data are well informed of new and current procedures, and the hydrographers are responsible for asking questions if there is something they do not understand.

\section{Collection of Sediment Data}

Surface-water activities in the KWSC include the collection, analysis, and publication of sediment data. The KWSC operates in adherence to sediment-related policies set forth by the OSW.

Responsibility for the sediment discipline was transferred from the Office of Water Quality (OWQ) to the OSW in 1985 (Office of Surface Water Technical Memorandum No. 92.08). The policies and procedures related to sediment followed by the KWSC are described in selected USGS publications and in memorandums issued by the OSW, the OWQ, and the USGS. Techniques adopted by the USGS and followed by the KWSC are presented in Knott and others (1992). The KWSC follows procedures presented in three USGS Techniques of WaterResources Investigations (TWRIs): Guy (1970), Guy and Norman (1970), and Porterfield (1972).

Although no additional TWRI chapters have been written to supersede the above-mentioned reports, Edwards and Glysson, 1988 (USGS OFR 86-531) essentially replaces Guy and Norman, 1970 (TWRI book 3, chap. C2) (Water Resources Division Memorandum No. 71.73, Office of Surface Water Technical Memorandum No. 88.17, and Office of Surface Water Technical Memorandum No. 93.01).

A summary of memorandums, issued since 1971, related to sediment and sediment transport is provided in Office of Surface Water Technical Memorandum No. 92.08. A summary of documentation that describes instrumentation and field methods for collecting sediment data is provided in Office of Surface Water Technical Memorandum No. 93.01.

\section{Sampling Procedures}

KWSC personnel collect suspended-sediment data by using sampling methods that include the single-vertical method, the Equal Discharge Increment (EDI) method, the Equal Width Increment (EWI) method, and the point-sample method. Another way to sample is by using an automatic sampler, which uses a pump to draw samples from the river or stream at scheduled intervals. For installation and use of automatic pumping-type samplers, the KWSC follows the criteria described in Edwards and Glysson (1988, p. 32).

Field methods for sediment sampling are documented in Office of Surface Water Technical Memorandum No. 93.01. Water samples obtained for the analysis of sediment concentration and particle size are not composited (Office of Surface Water Technical Memorandum No. 93.01 and Quality of Water Branch Technical Memorandum No. 76.17). The cone splitter is used for samples that are split, (Quality of Water Branch Technical Memorandum No. 80.17). (Currently, (2006), the Quality of Water Branch is referred to as the Office of Water Quality).

Policy for the collection and publication of bed-load data is provided in Office of Surface Water Technical Memorandum No. 90.08. This memorandum supersedes policy and guidelines provided in previous Quality of Water Branch Technical Memorandum Nos. 76.04, 77.07, 79.17, and 80.07, as well as Water Resources Division Memorandum No. 77.60. Among the policies stated in Office of Surface Water Technical Memorandum No. 90.08, which are followed by the $\mathrm{KWSC}$, is one stating that three cross-sectional procedures are used for bed-load sampling: the Single Equal Width Increment (SEWI) method, the Multiple Equal Width Increment (MEWI) method, and the Unequal Width Increment (UWI) method. Additionally, it is stated in Office of Surface Water Technical Memorandum No. 90.08 that it is the responsibility of field personnel to select the procedure that is optimal for the local condition. Bed-load samples are analyzed individually or as a composite. All samples are required to be analyzed individually until sampling variability for a particular site is understood by those analyzing the data.

The HSS chief is responsible for scheduling sedimentcollection activities at specific sites, and the KWSC WaterQuality Specialist is responsible for ensuring that KWSC personnel use correct procedures to collect sediment data. This individual establishes whether or not correct procedures are being used by discussing current procedures with individuals involved in sediment-data collection and reviewing pertinent memorandums and procedures with them, when necessary. The KWSC Water-Quality Specialist answers questions from KWSC personnel concerning sediment-sampling techniques. 


\section{Field Notes}

KWSC personnel are required to fill out a miscellaneous note sheet each time a site is visited for sediment sampling. The employee completes the note sheet in its entirety before leaving the site. Original observations written on the note sheets are not to be erased; data are corrected by crossing out the original observations and writing the correct information near the original value. The goal of placing information on the field note sheet is to describe the equipment and methods used during the site visit as well as to describe relevant conditions or changes (Office of Surface Water Technical Memorandum No. 91.15). For each site visit, information included on the note sheet includes, at minimum, site identification number and name, field personnel name, date, time, gage height, discharge information, and sampling equipment and methods used.

Upon completion of each field trip, field notes are placed in the current folder for that station; field notes are checked periodically. Presently (2006), the KWSC collects samples for lab analysis but does not compute the sediment record.

\section{Equipment}

Care and maintenance of the sediment-data-collection equipment is the responsibility of the field personnel who use the specific equipment. Parts replacement and repair of damaged equipment is accomplished by replacing the damaged part; replacement parts are obtained through the HSS chief or the KWSC Water-Quality Specialist. The KWSC Water-Quality Specialist is the responsible for ensuring that appropriate equipment is used at all sampling sites. Sampling equipment is selected based on the constituents that are being investigated, the type of analyses that will be performed, and site conditions, including velocity and maximum depth of water. The KWSC follows equipment-design criteria and guidelines referenced in Office of Surface Water Technical Memorandum No. 93.01.

\section{Sample Handling and Storage}

The quality of sediment data provided by a sediment laboratory is affected by the quality of the samples received from the field (Knott and others, 1992, p. 2). KWSC personnel are required to prepare sample labels, analysis instructions, and sample documentation according to guidelines presented in Knott and others (1992).

Sample containers are tightly sealed and stored in protective crates prior to field use. During field trips and prior to use, sample containers are stored in the field vehicle and shielded from direct sunlight. After the containers are filled with sediment samples, they are stored in the field vehicle and shielded from direct sunlight for the remainder of the field trip. Samples are delivered to the KWSC Sediment Lab after the field trip.

\section{High-Flow Conditions}

High-flow conditions at most streams are associated with high-energy conditions, unless the streams are subject to the effects of backwater. The sediment load and particle sizes associated with high flows are appreciable factors in sediment studies performed by the KWSC. Field personnel are instructed by the KWSC Water-Quality Specialist to ensure they are aware of their responsibilities in obtaining sediment samples at appropriate sites during high-flow conditions. The HSS chief or the project chief is responsible for ensuring that sediment samples are obtained during high-flow conditions. The individual collecting the sample is responsible for ensuring that the proper sampling equipment and methods are used during high-flow conditions. The KWSC Water-Quality Specialist is responsible for providing answers to KWSC personnel who have questions concerning high-flow sampling equipment or sampling procedures.

\section{Cold-Weather Conditions}

Sediment-sampling activities in the KWSC include obtaining samples during periods of subfreezing temperatures. During cold-weather conditions, field personnel should take every precaution to ensure their personal safety. Additionally, field personnel should attempt to ensure that floating slabs of ice do not damage equipment and ice crystals do not clog nozzles.

When floating slabs of ice pose the danger of damaging sampling equipment, such as during spring breakup, field personnel may manage only to obtain surface samples between the floating slabs of ice (Edwards and Glysson, 1988, p. 86). The procedure is noted on the field note sheet and sample label. When anchor ice and frazzle ice are present, it may be necessary to move the sampling equipment quickly through ice crystals to avoid clogging the nozzle. This procedure also is noted on the field note sheets and sample label.

\section{Site Documentation}

A station description is prepared for each new sediment-sampling site. At sampling sites where streamflow-gaging activities occur, the description of sediment activities is included in the streamflow-gaging-station description. A list of elements included in each station description, along with an explanation of what items are included with each element, is presented in the attachment to Office of Surface Water Technical Memorandum No. 91.15. At sites where only sediment samples are collected, the station descriptions are structured similarly to those for streamflow-gaging stations and contain similar informational items (Kennedy, 1983, p. 2). At sampling sites where gage houses have been installed, station descriptions are stored in the gage house for providing field personnel with information pertinent to sediment-sampling procedures for that particular site. Station descriptions are 
included in the field folder and are maintained in the office files. Each description includes specific information explaining where the site samples should be taken and what method should be used.

Field personnel assigned to specific field trips are responsible for ensuring that copies of station descriptions located at their gage houses are current. Station descriptions are kept current by the individual that processes the sediment-station data and are reviewed annually by the field office chief to ensure that they are current. When a deficiency is identified during a review of station descriptions, the deficiency is corrected by the reviewer. The reviewer informs the individual who worked the sediment record of the deficiencies and provides suggestions to correct it. The individual who worked the record is responsible for making the corrections.

A log of sampling activities is stored at each sampling site in the gage house.

\section{Processing and Analysis of Sediment Data}

Sediment and associated streamflow data are compiled to produce sediment records for specific sites. Data processing of periodic measurements consists of four steps: tabulation, evaluation, editing, and verification (Office of Surface Water Technical Memorandum No. 91.15). The KWSC follows the considerations and guidelines presented in Porterfield (1972), Guy (1969), and Office of Surface Water Technical Memorandum No. 91.15 in carrying out these four steps.

Presently (2006), the KWSC does not compute any daily sediment records.

The field office chief is responsible for ensuring that appropriate procedures are correctly applied in processing sediment data. Field notes and work sheets for each site are maintained in the current station folder while current year sediment data are being processed. After the record is complete, field notes and work sheets are maintained in the designated sediment-file folder.

\section{Sediment Laboratory}

The KWSC has a full service sediment laboratory where analyses are performed on samples submitted by many USGS and non-USGS customers. The laboratory receives an onsite review by appropriate technical or management personnel from the OSW every 3 years. These reviews examine all aspects of laboratory operations (Knott and others, 1993, p. 14). The KWSC Sediment Laboratory has a published quality-assurance plan (Shreve and Downs, 2005).

The sediment laboratory chief is primarily responsible for ensuring that appropriate equipment and procedures are used in the sediment laboratory. The laboratory is operated according to procedures described in Knott and others (1992) and
Guy (1969). KWSC personnel follow procedures for calibration and maintenance of equipment, analytical procedures, and documentation as described in Knott and others (1992) and Guy (1969).

The KWSC adheres to policies described in memorandums issued by OSW and OWQ, in addition to following guidelines and procedures described in Knott and others (1992) and Guy (1969). USGS policy on accepted methods of sediment-size determinations is outlined in Office of Surface Water Technical Memorandum No. 93.11. Fall diameter is analyzed in this laboratory by use of the pipet method. When sediment concentrations are determined by the filtration method, the type of filter used is Whatman 934 AH filter, as stated in Office of Surface Water Technical Memorandum No. 92.05, because the use of asbestos is no longer permitted in a USGS sediment laboratory,

\section{Sediment-Station Analysis}

A sediment station analysis is written for each sediment station operated by the KWSC each water year. The sediment station analysis is a summary of the sediment activities at the station for a given year. The analysis describes the coverage of sampling, the types of samples and sampling, changes that might affect sediment transport or the record, and the methods and reasoning used to compute the record. Information included in the sediment station analysis is presented in a thorough manner so that the checker and reviewer can determine from the analysis the adequacy of the activities in defining the record and in accomplishing the objectives defined for the station (Office of Surface Water Technical Memorandum No. 91.15).

Elements included in each sediment station analysis are listed in Office of Surface Water Technical Memorandum No. 91.15, along with descriptions of the elements and examples. The sediment-station analyses are maintained with the station file.

\section{Sediment-Analysis Results}

Sediment data are published in the annual water-data report or in individual project reports. Sediment data are organized and reported as described in Novak (1985) and Office of Surface Water Technical Memorandum No. 91.15.

\section{Sediment-Data Storage}

All sediment field notes and written analytical results from the KWSC Sediment Laboratory are stored in the station folder or in the SLEDS database. 


\section{Database Management}

Surface-water data have been collected by USGS personnel and stored in computer databases for more than 20 years. Proper storage and maintenance of surface-water data are critical components in the effective use of those data. Descriptions of policies and procedures associated with these functions are quickly outdated because computer hardware and software used in the processing and storage of surface-water data are continually changing.

Database management in the KWSC is done by a team of individuals for each different type of data. The overall process of storing surface-water data collected at continuous-recording gaging stations includes using ADAPS and the standard USGS database. Instantaneous peak discharges and peak stages are stored in the Peak Flow File. Ground-water data are stored in GWSI and water-quality data are stored in QWDATA. The HSS chief has the final responsibility for ensuring that the surface-water database (ADAPS) and the Peak Flow File is current and accurate.

\section{Publication of Surface-Water Data}

The Act of Congress (Organic Act) that created the U.S. Geological Survey in 1879 established the USGS obligation to make public the results of its investigations and research and to perform, on a continuing, systematic, and scientific basis, the investigation of the geologic structure, mineral resources, and products of the National domain (Alt and Iseri, 1986, p. 4). Fulfilling this obligation includes the publication of surface-water data and the interpretive information derived from the analyses of surface-water data.

\section{Publication Policy}

The USGS has created specific policies pertaining to publication and interpretation of data. All personnel, including those of the KWSC, are required to abide by those policies. A brief summary of goals, procedures, and policies are presented in Alt and Iseri (1986, p. 4-37).

All information obtained through investigations and observations by USGS staff or its contractors must be held confidential and not be disclosed to others until the information is made available to all, impartially and simultaneously, through Director-approved formal publication or other means of public release, except to the extent that such release is mandated by law (Alt and Iseri, 1986, p. 14). With the approval of the Director, hydrologic measurements resulting from observations and laboratory analyses, after they have been reviewed for accuracy by designated USGS personnel, have been excluded from the requirements to hold unpublished information confidential (Alt and Iseri, 1986, p. 15).
All interpretive writings in which the USGS has a proprietary interest, including abstracts, letters to the editor, and all writings that show the author's title and USGS affiliation must be approved by the Director before release for publication. The objectives of the Director's review are to final-check the technical quality of the writing, make certain that it meets USGS publication standards, and ensure consistency with policies of the USGS and the U.S. Department of the Interior. Director's approval ensures that each publication or writing (1) is impartial and objective, (2) has conclusions that do not compromise the USGS's official position, (3) does not take an unwarranted advocacy position, and (4) does not criticize or compete with other governmental agencies or the private sector (Hansen, 1991, p. 10).

\section{Types of Publications}

Various types of book publications released by the USGS are available in which surface-water data and data analyses are presented. Publications of the formal series include the Water-Supply Paper, Professional Paper, Bulletin, Circular, Techniques of Water-Resources Investigations, Special Reports, and Selected Papers in the Hydrologic Sciences (Alt and Iseri, 1986, p. 42). Publications in the informal series include the Water-Resources Investigations Report, Open-File Report, and Administrative Report (Alt and Iseri, 1986, p. 52). Included in the Open-File Report series are data reports. Surface-water data collected by the KWSC are published annually in the series titled "U.S. Geological Survey Water-Data Reports." Factors considered by the KWSC when deciding which form of publication should be used in presenting various types of information are presented in Green (1991, p. 14).

On December 29, 2003, U.S. Geological Survey Manual 1100.3-U.S. Geological Survey Publication Serieswas issued with the following revised publications series':

- Administrative Report

- Circular

- Data Series

- Fact Sheet

- General Information Product

- Open-File Report

- Professional Paper

- Scientific Investigations Map

- Scientific Investigations Report

- Techniques and Methods

Detailed definitions of each new series are available online at http://www.usgs.gov/usgs-manual/1100/1100-3appendixa.pdf 


\section{Review Process}

Procedures for publication and requirements for manuscript review are summarized in Hansen (1991, p. 36-41). The KWSC fulfills those requirements for review and approval of publications prior to printing and distribution. All publications written by USGS scientists in connection with their official duties must be approved by the USGS Director. At least two technical reviews of each manuscript are required (Hansen, 1991, p. 36). Competent and thorough editorial and technical review is the most certain way to improve and assure the high quality of the final publication (Moore and others, 1990, p. 24). Principles of editorial review and responsibilities of reviewers and authors are presented in Moore and others (1990, p. 24-49). All Open-File Reports published by the KWSC receive editorial review.

For publications other than the annual water-data report, it is KWSC policy for authors to provide written responses to all significant comments and suggestions provided by the colleague reviewers. Colleague reviewers' memorandums, authors' response memorandums, and marked up review copies are maintained with the draft manuscript that is submitted for USGS Director's approval.

The KWSC Director is ultimately responsible for presenting complete and accurate information in the KWSC annual water-data report; however, the HSS chief oversees all facets of the data-collection, data analysis, and report-production process. The HSS chief depends on the three field office chiefs for their valuable input. The KWSC Director has been delegated authority to approve the annual water-data report for publication.

\section{Safety}

Performing work activities in a manner that ensures the safety of personnel and others is the highest priority for the USGS and the KWSC. Beyond the obvious negative effect unsafe conditions can have on personnel, such as accidents and personal injuries, they also can have a direct effect on the quality of surface-water data and data analysis. For example, errors may be made when an individual's attention to detail is compromised because a dangerous condition is creating a distraction. The KWSC communicates information and directives related to safety to all personnel by individual and group inhouse training and verbal and written communication between management and staff so that personnel are aware of, and follow, established policies and procedures that promote all aspects of safety. Specific policies and procedures related to safety can be found posted on the safety bulletin board and by request to the KWSC safety officer. It is the responsibility of each employee to attend the required safety training provided by the KWSC, adhere to USGS and KWSC safety policies, and contribute to the development of KWSC policies by communicating to their supervisor the need for improvements.

The KWSC has a designated safety officer. The safety officer's duties include assisting the Director in making safety policies and procedures known to KWSC personnel.

Personnel who have questions or concerns pertaining to safety, or who have suggestions for improving some aspect of safety, should direct those questions, concerns, and suggestions to their supervisor or the KWSC safety officer.

\section{Training}

Ensuring that personnel obtain knowledge of correct methods and procedures is a vital aspect of maintaining the quality of surface-water data and analysis. The KWSC increases the quality of work and eliminates the source of many potential errors by providing appropriate training to personnel.

The KWSC has a training officer who ensures that all employees are made aware of available training opportunities. It also is the responsibility of each supervisor and management to ensure that personnel receive appropriate training. Training includes formal courses presented by the USGS, local universities, and other institutions. An extremely important form of training includes one-on-one and in-house training sessions provided by more experienced personnel. Part of each employee's performance plan includes discussions about training. Ideally, the supervisor and employee meet 2 to 4 times a year to discuss the employee's performance and needed training.

\section{Summary}

Information included in this Surface Water QualityAssurance Plan documents the policies and procedures of the Kentucky Water Science Center that ensure high-quality collection, processing, storage, analysis, and publication of surface-water data. Specific types of surface-water data discussed in this report include stage, streamflow, sediment, and basin characteristics. The roles and responsibilities of Kentucky Water Science Center personnel for carrying out these policies and procedures are presented along with issues related to management of the computer database and issues related to employee safety and training. 


\section{References Cited}

Alt, D.F., and Iseri, K.T., eds., 1986, Water Resources Division publication guide, Volume 1, Publication policy and text preparation ( $2 \mathrm{~d}$ ed.): U.S. Geological Survey Open-File Report 87-205, accessed February 28, 2006, at http://pubs. er.usgs.gov/pubs/ofr/ofr 87205

Arcement, G.J., and Schneider, V.R., 1989, Guide for selecting Manning's roughness coefficients for natural channels and flood plains: U.S. Geological Survey Water-Supply Paper 2339, 38 p.

Barnes, H.B, 1967, Roughness characteristics of natural channels: U.S. Geological Survey Water-Supply Paper 1849, 213 p.

Benson, M.A., and Dalrymple, Tate, 1967, General field and office procedures for indirect discharge measurements: U.S. Geological Survey Techniques of Water-Resources Investigations, book 3, chap. A1, 30 .

Bodhaine, G.L., 1982, Measurement of peak discharge at culverts by indirect methods: U.S. Geological Survey Techniques of Water-Resources Investigations, book 3, chap. A3, $60 \mathrm{p}$.

Buchanan, T.J., and Somers, W.P., 1969, Discharge measurements at gaging stations: U.S. Geological Survey Techniques of Water-Resources Investigations, book 3, chap. A8, $65 \mathrm{p}$.

Carter, R.W., and Davidian, Jacob, 1968, General procedures for gaging streams: U.S. Geological Survey Techniques of Water-Resources Investigations, book 3, chap. A6, 13 p.

Dalrymple, Tate, and Benson, M.A., 1967, Measurement of peak discharge by the slope-area method: U.S. Geological Survey Techniques of Water-Resources Investigations, book 3, chap. A2, 12 p.

Davidian, Jacob, 1984, Computation of water-surface profiles in open channels: U.S. Geological Survey Techniques of Water-Resources Investigations, book 3, chap. A15, 48 p.

Edwards, T.K., and Glysson, G.D., 1988, Field methods for measurement of fluvial sediment: U.S. Geological Survey Open-File Report 86-531, 118 p.

Green, J.H., 1991, WRD project and report management guide: U.S. Geological Survey Open-File Report 91-224, $152 \mathrm{p}$.

Guy, H.P., 1969, Laboratory theory and methods for sediment analysis: U.S. Geological Survey Techniques of WaterResources Investigations, book 5, chap. C1, 58 p.
Guy, H.P., 1970, Fluvial sediment concepts: U.S. Geological Survey Techniques of Water-Resources Investigations, book 3, chap. C1, 55 p.

Guy, H.P., and Norman, V.W., 1970, Field methods for measurement of fluvial sediment: U.S. Geological Survey Techniques of Water-Resources Investigations, book 3, chap. 2,59 p.

Hansen, W.R., ed., 1991, Suggestions to authors of the Reports of the United States Geological Survey (7th ed.): U.S. Geological Survey, 289 p.

Hubbard, E.F., 1992, Policy recommendations for management and retention of hydrologic data of the U.S. Geological Survey: U.S. Geological Survey Open-File Report 92-56, 32 p.

Kennedy, E.J., 1983, Computation of continuous records of streamflow: U.S. Geological Survey Techniques of WaterResources Investigations, book 3, chap. A13, 53 p.

Kennedy, E.J., 1984, Discharge ratings at gaging stations: U.S. Geological Survey Techniques of Water-Resources Investigations, book 3, chap. A10, 59 p.

Kennedy, E.J., 1990, Levels at streamflow gaging stations: U.S. Geological Survey Techniques of Water-Resources Investigations, book 3, chap. A19, 31 p.

Kilpatrick, F.A., and Schneider, V.R., 1983, Use of flumes in measuring discharge: U.S. Geological Survey Techniques of Water-Resources Investigations, book 3, chap. A14, 46 p.

Knott, J.M., Glysson, G.D., Malo, B.A., and Schroder, L.J., 1993, Quality assurance plan for the collection and processing of sediment data by the U.S. Geological Survey, Water Resources Division: U.S. Geological Survey Open-File Report 92-499, 18 p.

Knott, J.M, Sholar, C.J., and Matthes, W.J., 1992, Quality assurance guidelines for the analysis of sediment concentration by the U.S. Geological Survey sediment laboratories: U.S. Geological Survey Open-File Report 92-33, 22 p.

Matthai, H.F., 1967, Measurement of peak discharge at width contractions by indirect methods: U.S. Geological Survey Techniques of Water-Resources Investigations, book 3, chap. A4, 44 p.

Moore, J.E, Aronson, D.A., Green, J.H., and Puente, Celso, 1990, Report planning, preparation, and review guide: U.S. Geological Survey Open-File Report 89-275, 81 p.

Novak, C.E., 1985, WRD data reports preparation guide: Techniques of Water-Resources Investigations, book 3, chap. C3, 66 p. 
Porterfield, George, 1972, Computation of fluvial-sediment discharge: U.S. Geological Survey Techniques of WaterResources Investigations, book 3, chap. C3, 66 p.

Rantz, S.E., and others, 1982, Measurements and computation of streamflow, volumes 1 and 2: U.S. Geological Survey Water-Supply Paper 2175, 631 p.

Sauer, V.B., and Meyer, R.W., 1992, Determination of errors in individual discharge measurements: U.S. Geological Survey Open-File Report 92-144, 21 p.

Shearman, J.O., 1990, User's manual for WSPRO_A computer model for water surface profile computations: U.S. Federal Highway Administration Report, FHWA-IP-89-027, 187 p.
Shreve, E.A. and Downs, A.C., 2005, Quality-assurance for the analysis of fluvial sediment by the U.S. Geological Survey Kentucky Water Science Center Sediment Laboratory: U.S. Geological Survey Open-File Report 2005-1230, accessed February 24, 2006, at http://pubs.usgs.gov/ of $/ 2005 / 1230 /$.

Smoot, G.F., and Novak, C.E., 1968, Calibration and maintenance of vertical-axis type current meters: U.S. Geological Survey Techniques of Water-Resources Investigations, book 8 , chap. B2, 15 p. 


\section{Appendixes 1 through 6}




\section{Appendix 1. U.S. Geological Survey Technical Memorandums Cited.}

The following memorandums are cited in the KWSC Surface Water Quality-Assurance Plan. The memorandums are provided in their entirety in a separate report by the Office of Surface Water.

- Office of Surface Water Technical Memorandum No. 99.06 http://water.usgs.gov/admin/memo/SW/sw99.06.html

- Office of Surface Water Technical Memorandum No. 93.12 http://water.usgs.gov/admin/memo/SW/sw93.12.html

- Office of Surface Water Technical Memorandum No. 93.11 http://water.usgs.gov/admin/memo/SW/sw93.11.html

- Office of Surface Water Technical Memorandum No. 93.07 http://water.usgs.gov/admin/memo/SW/sw93.07.html

- Office of Surface Water Technical Memorandum No. 92.11 http://water.usgs.gov/admin/memo/SW/sw92.11.html

- Office of Surface Water Technical Memorandum No. 92.10 http://water.usgs.gov/admin/memo/SW/sw92.10.html

- Office of Surface Water Technical Memorandum No. 92.09 http://water.usgs.gov/admin/memo/SW/sw92.09.html

- Office of Surface Water Technical Memorandum No. 92.08 http://water.usgs.gov/admin/memo/SW/sw92.08.html

- Office of Surface Water Technical Memorandum No. 92.05 http://water.usgs.gov/admin/memo/SW/sw92.05.html

- Office of Surface Water Technical Memorandum No. 92.04 http://water.usgs.gov/admin/memo/SW/sw92.04.html

- Office of Surface Water Technical Memorandum No. 91.15 http://water.usgs.gov/admin/memo/SW/sw91.15.html

- Office of Surface Water Technical Memorandum No. 90.08 http://water.usgs.gov/admin/memo/SW/sw90.08.html

- Office of Surface Water Technical Memorandum No. 90.01 http://water.usgs.gov/admin/memo/SW/sw90.01.html
- Office of Surface Water Technical Memorandum No. 89.08 http://water.usgs.gov/admin/memo/SW/sw89.08.html

- Office of Surface Water Technical Memorandum No. 89.07 http://water.usgs.gov/admin/memo/SW/sw89.07.html

- Office of Surface Water Technical Memorandum No. 88.18 http://water.usgs.gov/admin/memo/SW/sw88.18.html

- Office of Surface Water Technical Memorandum No. 88.07 http://water.usgs.gov/admin/memo/SW/sw88.07.html

- Office of Surface Water Technical Memorandum No. 87.05 http://water.usgs.gov/admin/memo/SW/sw87.05.html

- Office of Surface Water Technical Memorandum No. 85.17 http://water.usgs.gov/admin/memo/SW/sw85.17.html

- Office of Surface Water Technical Memorandum No. 85.14 http://water.usgs.gov/admin/memo/SW/sw85.14.html

- Office of Surface Water Technical Memorandum No. 84.05 http://water.usgs.gov/admin/memo/SW/sw84.05.html

- Office of Surface Water Technical Memorandum No. 83.07 http://water.usgs.gov/admin/memo/SW/sw83.07.html

- Water Resources Division Memorandum No. 92.59 http://water.usgs.gov/admin/memo/policy/wrdpolicy92.059. html

- Quality of Water Branch Technical Memorandum No. 80.17 http://water.usgs.gov/admin/memo/QW/qw80.17.html

- Quality of Water Branch Technical Memorandum No. 76.17 http://water.usgs.gov/admin/memo/QW/qw76.17.html 

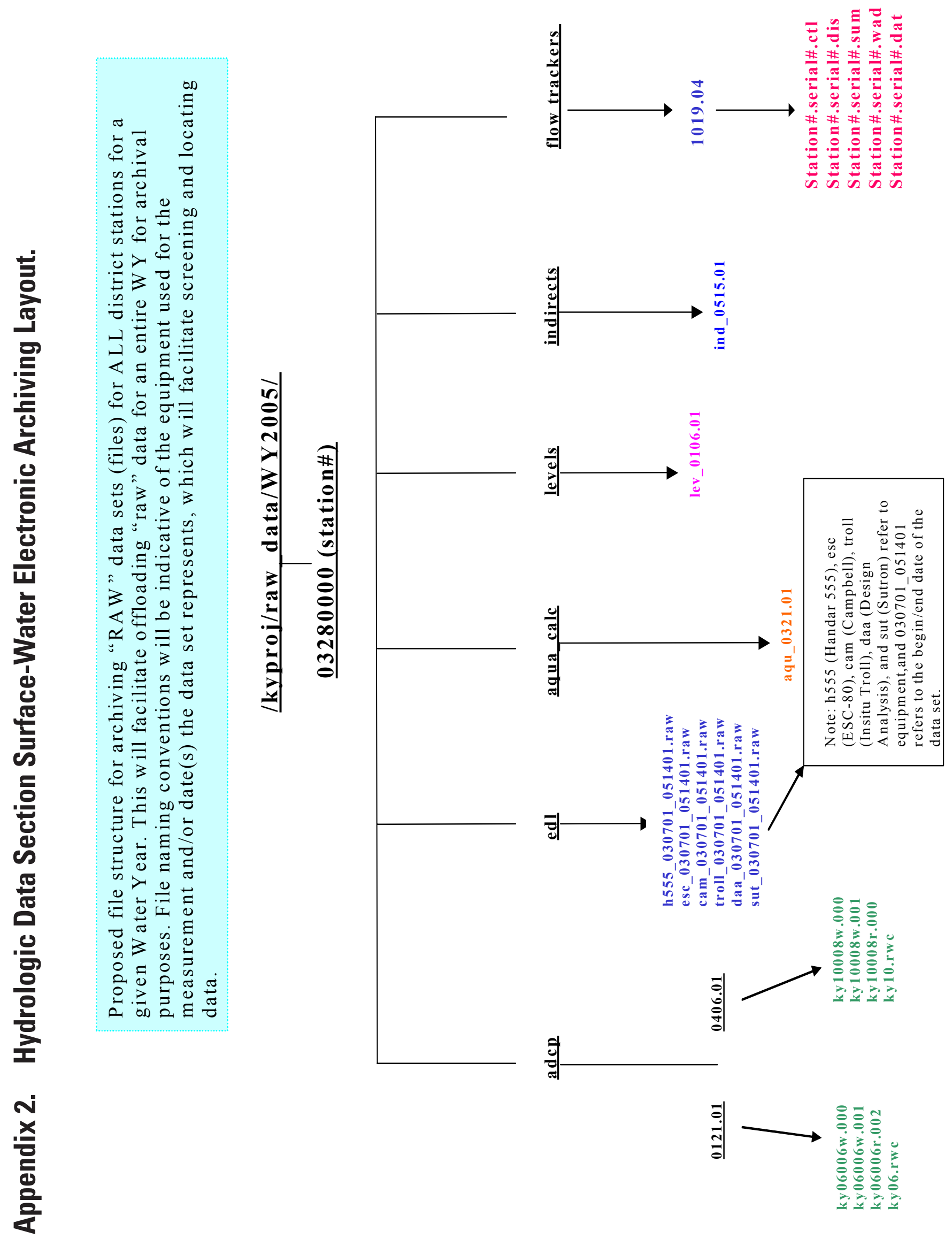


\title{
Appendix 3. Example of a Kentucky Water Science Center Station Description.
}

\author{
UNITED STATES \\ DEPARTMENT OF THE INTERIOR \\ U.S. GEOLOGICAL SURVEY \\ WATER RESOURCES DISCIPLINE
}

Revised: C.R. Moses 03/30/2005

\section{STATION DESCRIPTION.--RED RIVER AT CLAY CITY, KY}

STATION NUMBER.--03283500

LOCATION.--Lat 37051'53", long 8356'01", Powell County, Hydrologic Unit 05100204, on right bank $25 \mathrm{ft}$ upstream of bridge on State Highway 15 at Powell County Water Plant, 0.1 nmi downstream from Skinner Branch, 0.4 nmi upstream from Brush Creek, 0.5 mi west of Clay City, and at mi 21.6.

ROAD LOG.--From the junction of State Road 15 and the Mountain Parkway, drive north 0.6 mi to the bridge over Red River. The gage is located at the pumping station on the right bank $25 \mathrm{ft}$ upstream of State Highway 15 bridge.

DRAINAGE AREA.--362 $\mathrm{mi}^{2}$.

HISTORY.--Established October 21, 1930 by U.S. Geological Survey. Re-established April 26, 1938 at same site and datum. Moved $50 \mathrm{ft}$ upstream on August 13, 1975 at same datum. Prior to August 14, 1939 non-recording gages at former site. A creststage gage was installed July 28, 1993 for peak verification. March 25, 1998, removed servo-manometer/graphic recorder/560A DCP and installed Sutron Accubar Pressure Sensor and 555 DCP.

GAGE.--Vaisala 555 Data Collection Platform (phone 606-663-4821) interfaced with a Sutron Accubar Pressure Sensor, housed in a steel-lox building $20 \mathrm{ft}$ downstream of water plant and referred to a wire-weight gage attached to the downstream handrail of Hwy 15 bridge. Check-bar reads $35.253 \mathrm{ft}$, gage datum. The orifice is fastened to the downstream intake stand-pipe of the pump house. The crest-stage gage has an index elevation of $17.993 \mathrm{ft}$, gage datum.

DATUM OF GAGE.--600.47 ft above NGVD of 1929 (levels by U.S. Army Corps of Engineers).

DATE OF LAST LEVELS.--September 21, 2001.

REFERENCE MARKS.--RM-15: 2" aluminum tablet located on the left upstream handrail of bridge. Elevation, $35.911 \mathrm{ft}$, gage datum.

RM-16: Chiseled square on the right downstream handrail of bridge. Elevation, $35.567 \mathrm{ft}$, gage datum (origin).

RM-17: Chisled square on gage house floor at doorway. Elevation, $26.715 \mathrm{ft}$, gage datum.

RM-18: Chiseled square on top of center line of culvert $20 \mathrm{ft}$ streamward from gage house upstream side of highway. Elevation, $24.643 \mathrm{ft}$, gage datum. 
RM-19: Top of bolt on right upstream bridge footer. Elevation, $25.734 \mathrm{ft}$, gage datum.

RM-20: Chisled square on right upstream handrail of bridge. Elevation, $35.797 \mathrm{ft}$, gage datum.

CHANNEL AND CONTROL.--The low to medium water control is a sand bar with an island midstream about $400 \mathrm{ft}$ downstream of the gage. Willows growing on the island may collect drift to some extent, causing numerous shifts. Channel control exist in high stages. Streambed is composed of gravel and cobbles and is probably permanent. Channel is straight for 1,500 $\mathrm{ft}$ upstream and $500 \mathrm{ft}$ downstream of gage. Left bank cultivated and is overflowed occasionally (see remarks in DISCHARGE MEASUREMENT paragraph). Right bank is high and seldom overflowed.

DISCHARGE MEASUREMENTS.--Low-water measurements made by wading in the vicinity of the control. Medium and high-water measurements made from downstream side of highway bridge. Station markings are painted in 5-ft intervals with initial point at left end of downstream handrail. One channel at low and two at high stages. During extreme high flows, road overflow may occur about $0.5 \mathrm{mi}$ east of the gage. This flow would bypass the gage. In this instance, flow must be measured at the gage bridge plus any overflow. Measurement can also be obtained from the Mountain Parkway bridge crossing. See attachment for traffic control plan.

POINT OF ZERO FLOW.--Extremely variable. Determinations have varied from 0.5 to $1.0 \mathrm{ft}$.

FLOODS.--Maximum discharge, 28,800 ft³/s, December 9, 1978, gage-height, $26.75 \mathrm{ft}$.

WINTER FLOW.--Ice effect during most winters.

REGULATION AND DIVERSION.--A gas transmission compressor station, located 5.0 mi northwest of the gaging station, has an emergency water supply consisting of an intake structure about $75 \mathrm{ft}$ upstream of the gage and a 6-in. pipe line running back to the plant. They estimate the capacity to be 150 gallons per minute. Any water removed from the river is either evaporated or discharged into Lulbegrud Creek, which discharges into Red River about 10.0 mi downstream of the gage. The plant is normally supplied from Lulbegrud Creek and an associated lake. The amount of water drawn from Red River is considered to be negligible.

COOPERATION.--U.S. Army Corps of Engineers-Louisville District and Kentucky River Authority.

ACCURACY.--Records good.

SKETCH.--On file in Kentucky Water Science Center, Louisville, Ky.

PHOTOGRAPHS.--On file in Kentucky Water Science Center, Louisville, Ky.

QUADRANGLE.--F-24-c. 


\title{
Appendix 4. Example of a Kentucky Water Science Center Station Analysis.
}

\author{
03283500 RED RIVER AT CLAY CITY, KY \\ STATION ANALYSIS, 2004 WY
}

RECORDS.--Continuous streamflow. Discharge measurement $(\mathrm{Qm})$ obtained about every 8 weeks.

EQUIPMENT.--Vaisala 555 Data Collection Platform (DCP) interfaced with a Sutron Accubar Pressure Sensor (PS) housed in a steel-lox building $20 \mathrm{ft}$ downstream of Clay City water plant. Wire-weight gage (WWG) located on the downstream handrail of bridge serves as the reference gage. There is a crest-stage gage (CSG) for peak verification.

HYDROLOGIC CONDITIONS.--Flow diversions by Clay City Water Plant, which can be significant during periods of low flow.

GAGE-HEIGHT RECORD.--Good record was obtained throughout the current water year except Nov 13, Dec 24 to Jan 5, Feb 6-8, and Mar 6-7 when the pressure gage was leaking.

DATUM CORRECTIONS.--Levels run September 21, 2001 found the WWG reading .026 ft low and was reset to correct datum at that time. Datum corrections shown on the primaries were adjustments of the DCP readings to agree with the WWG, which were prorated between gage inspections unless otherwise noted. See datum correction sheets.

RATING.--The low and low to medium water control is a sand and gravel bar with an island midstream located about $400 \mathrm{ft}$ downstream of gage, which is subject to variable shifts due to the movement of bottom material and aquatic growth. Channel control exists at medium and high stages.

Discharge measurements (Qms) through No. 631 were available for this analysis, of which Nos. 623-629 were made during the current water year. Qms ranged in stage from $2.32 \mathrm{ft}$ to $4.45 \mathrm{ft}$ and in discharge from $83.3 \mathrm{ft}^{3} / \mathrm{s}$ to $618 \mathrm{ft}^{3} / \mathrm{s}$. Rating No. 19 was continued in use.

\section{SHIFT ANALYSIS}

The 2004 WY began with a -.10 ft shift as indicated by QM 623, made Oct 3. This shift was used until the rise on Oct 27 when the leaves were removed from the control. QM 624, made Nov 18, indicated 0 shift and no shift was used until the rise on Jan 6. QM 625, made Jan 14, indicated a $+.10 \mathrm{ft}$ shift which was put in on the Jan 6 rise and used until Feb 6 when a $+.15 \mathrm{ft}$ shift was applied due to more scour of the control. This shift was based on QM 626, made Mar 11, and was used until the rise on April 14. QM 627, made May 25, indicated a -.13 ft shift which was put in on the recession of the April 14 rise and carried to the rise on May 31. The -.13 ft shift was increased to a $-.18 \mathrm{ft}$ shift on the recession of the May 31 rise as indicated by QMs 628 and 629 , made July 15 and Aug 24, respectively. QM 630, made Oct 7, indicated a large negative shift and a check measurement (631) was made. QM 631 indicated a -.35 ft shift and was given more weight then QM 630. The .-35 ft shift was put in on the recession of the rise on Sept 18 when more sand and gravel were deposited on the control. The $2004 \mathrm{WY}$ ended with a $-.35 \mathrm{ft}$ shift.

See variable shift values sheet, 9-213-A, and rating curve for V-diagrams used during the year. 
DISCHARGE.--Discharges computed by applying 24 readings per day from the DCP to Rating No. 19 with indicated shifts and datum corrections as shown on primary computations sheets. Discharges for the year hydrographically compared with 03282500 Red River near Hazel Green, KY. Daily discharges are stored in DD-1 "Discharge, in cfs" for statistical computations.

SPECIAL COMPUTATIONS.--For the periods of Nov 13, Dec 24 to Jan 5, Feb 6-8, and Mar 6-7 due to nitrogen leaks, discharges were estimated based on hydrographic comparison with 03282500 Red River near Hazel Green, KY, gage-height plots, trend of flow, and weather records. Air temperature and precipitation data for Lexington, KY obtained from the University of Kentucky Agricultural Weather Center web site.

REMARKS.--Records good except for those estimated, which are poor.

Prepared by: J Hurst 11/19/2004

Checked by: S.B. Pickard 12/08/2004

Reviewed by: C.R. Moses 03/30/2005 

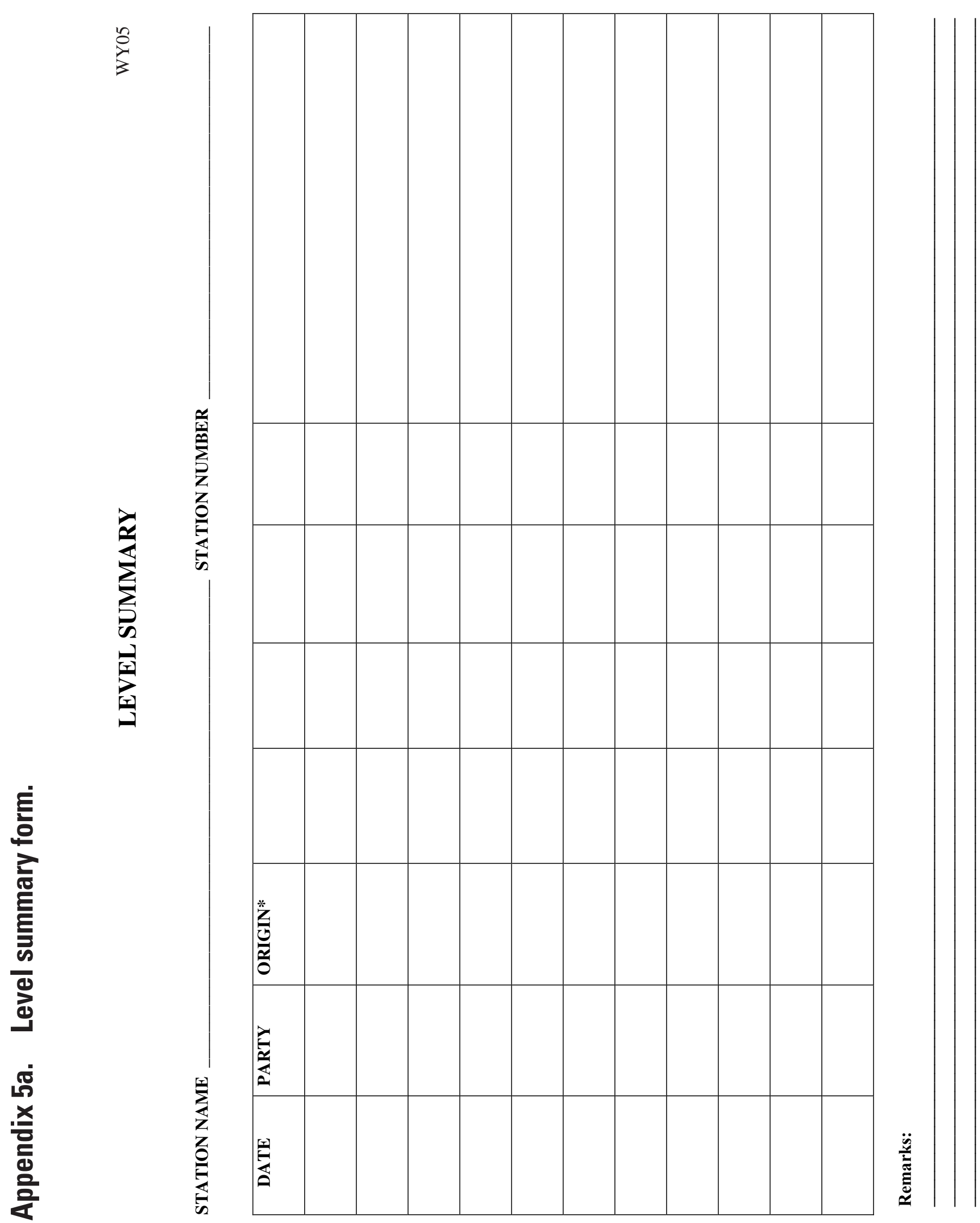
E
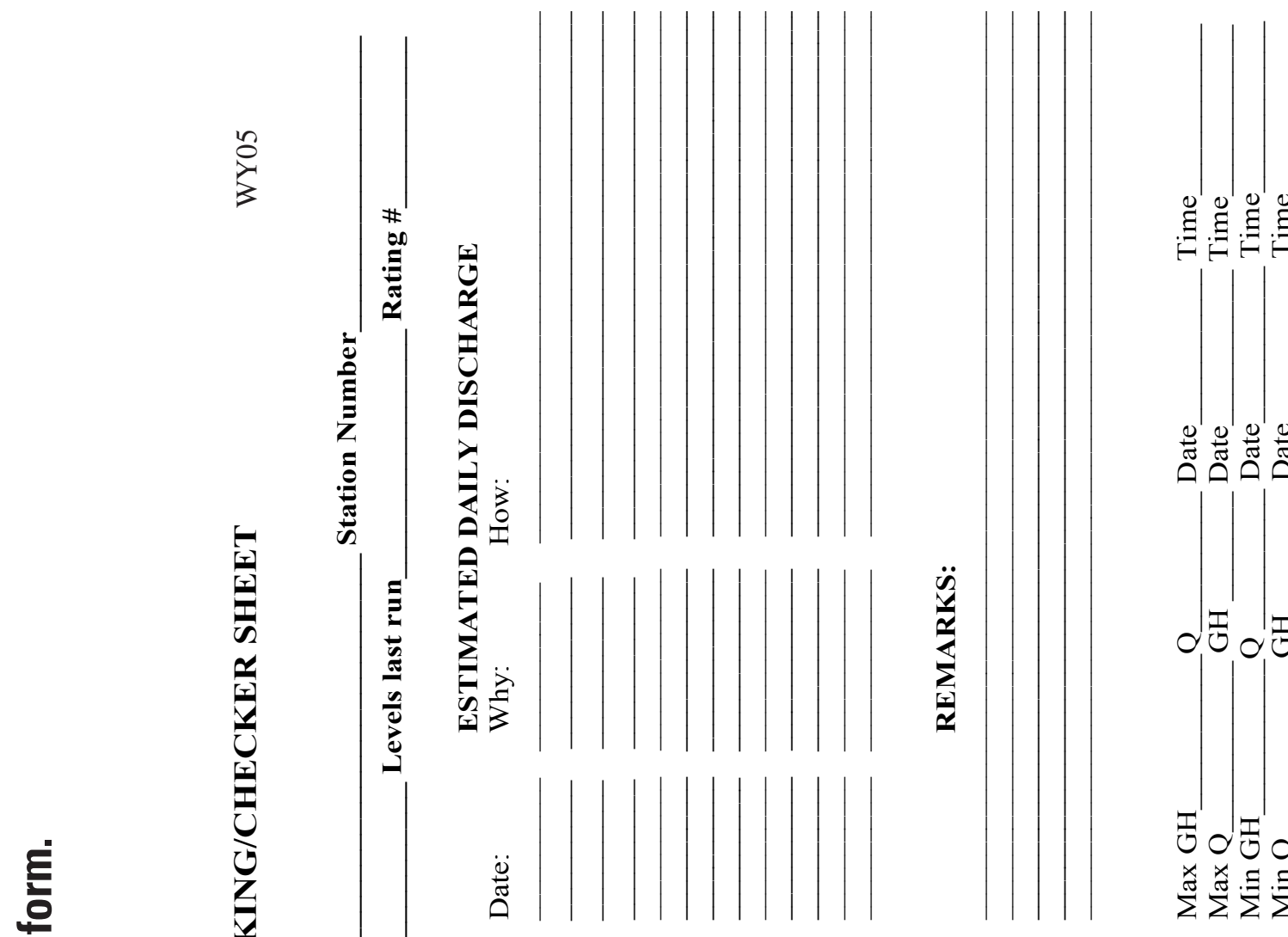

$\bar{v}$

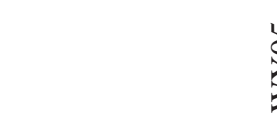

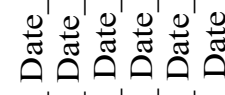
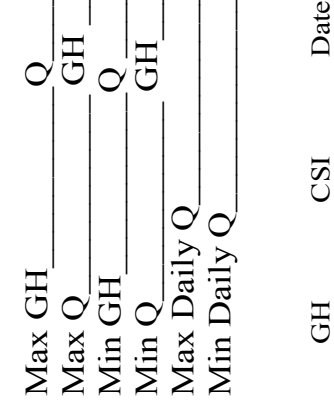

c

눌

$\frac{\operatorname{coc}}{\mathrm{d}}$
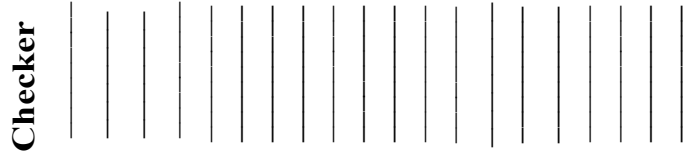

U

$\frac{3}{3}$

||

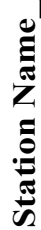

弪

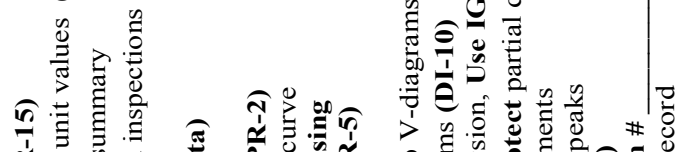

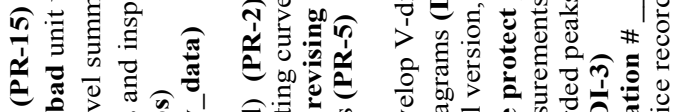

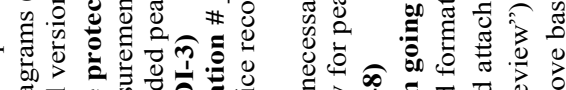

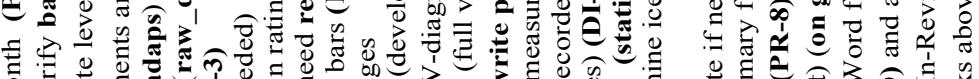

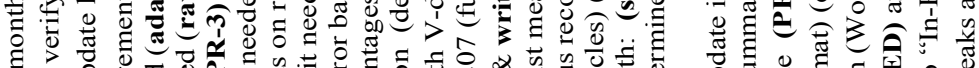

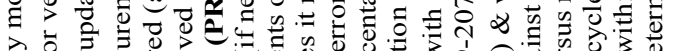

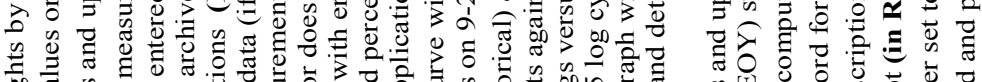

ลิำ

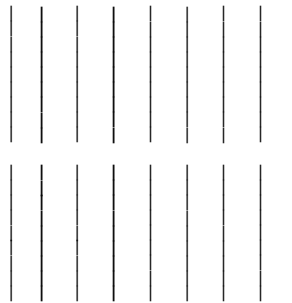

贡

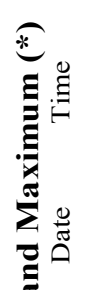

要

เก

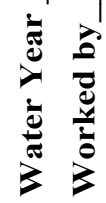

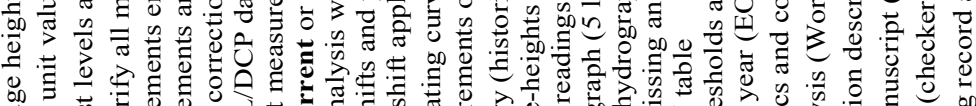

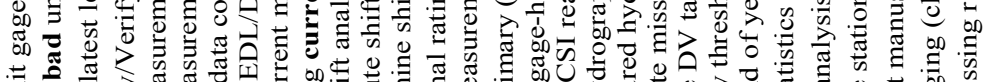

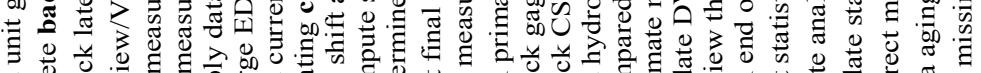

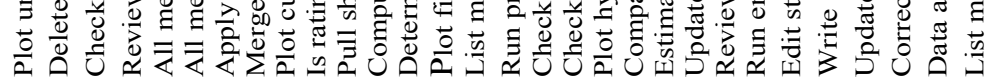


Appendix 5c. Annual surface-water data reviewer form.

\section{ANNUAL SURFACE-WATER DATA REVIEWER SHEET}

STATION NUMBER

WATER YEAR

STATION NAME

WORKED BY: CHECKED BY: REVIEWED BY:

\section{FIELD WORK}

MEASUREMENTS:

GAGE-HEIGHT RECORD:

LEVELS:

PEAKS:

$\underline{9-207}$

SHIFTS/ PERCENT DIFFERENCES/ FILLED OUT COMPLETE:

RATING

CURRENT/ NEEDS REVISION/ DRAWN PROPERLY:

ALL MEASUREMENTS PLOTTED:

\section{PRIMARY COMPUTATIONS}

DATA CORRECTIONS DISTRIBUTION:

SHIFT DISTRIBUTION:

ESTIMATED RECORD:

HYDROGRAPH COMPARISON:

STATION ANALYSIS

STATION DESCRIPTION:

STATISTICS/ DAILY VALUES TABLE/ MANUSCRIPT

DATA AGED (set to “Approved"):

COMMENTS: 
Appendixes $\quad 41$

है

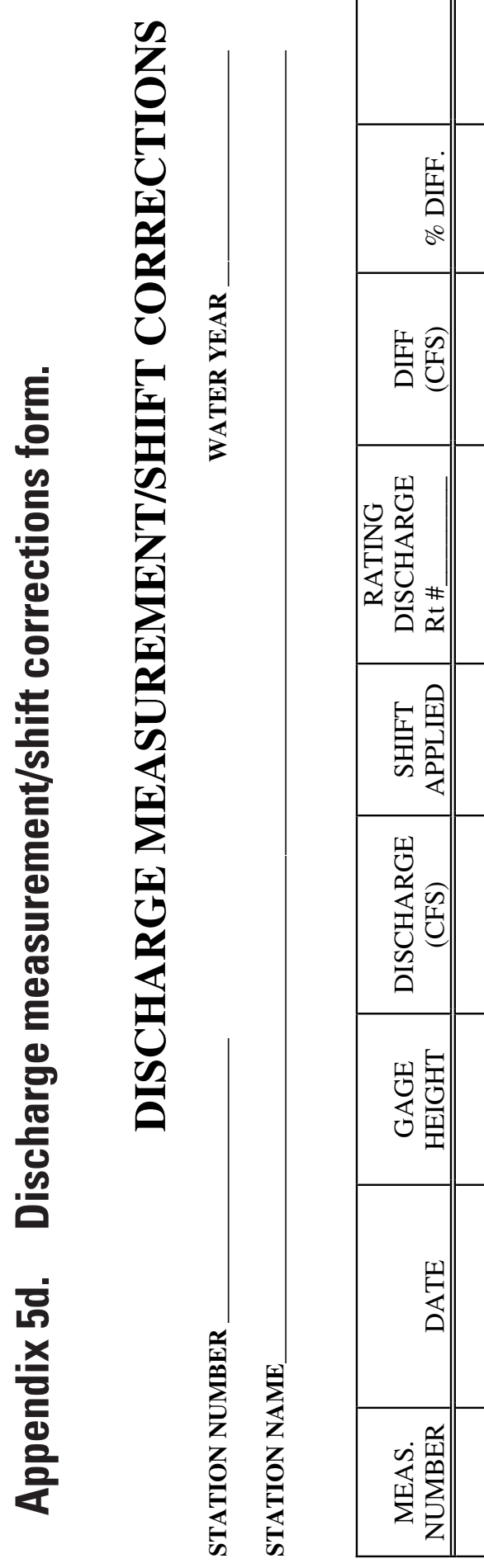



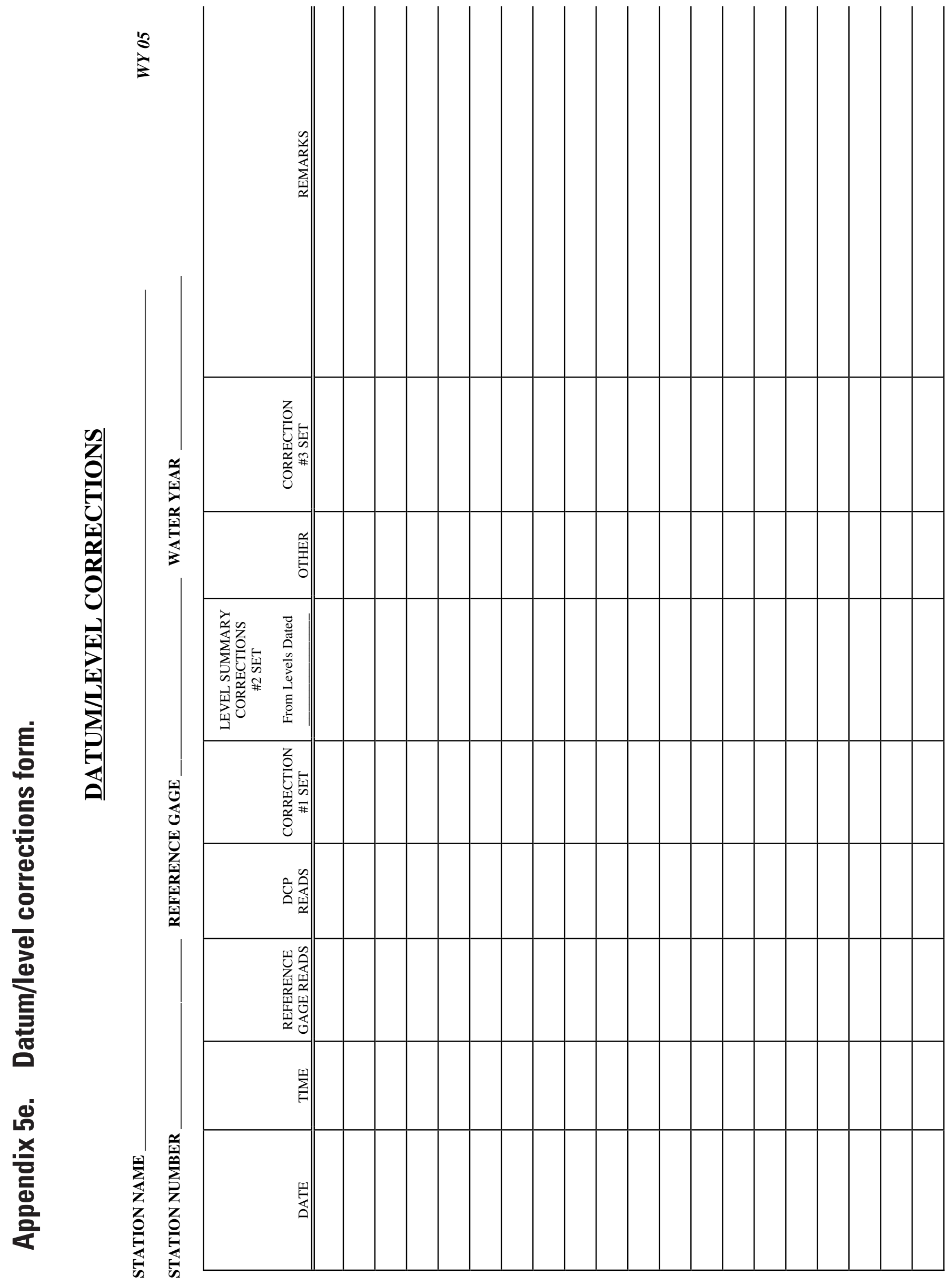


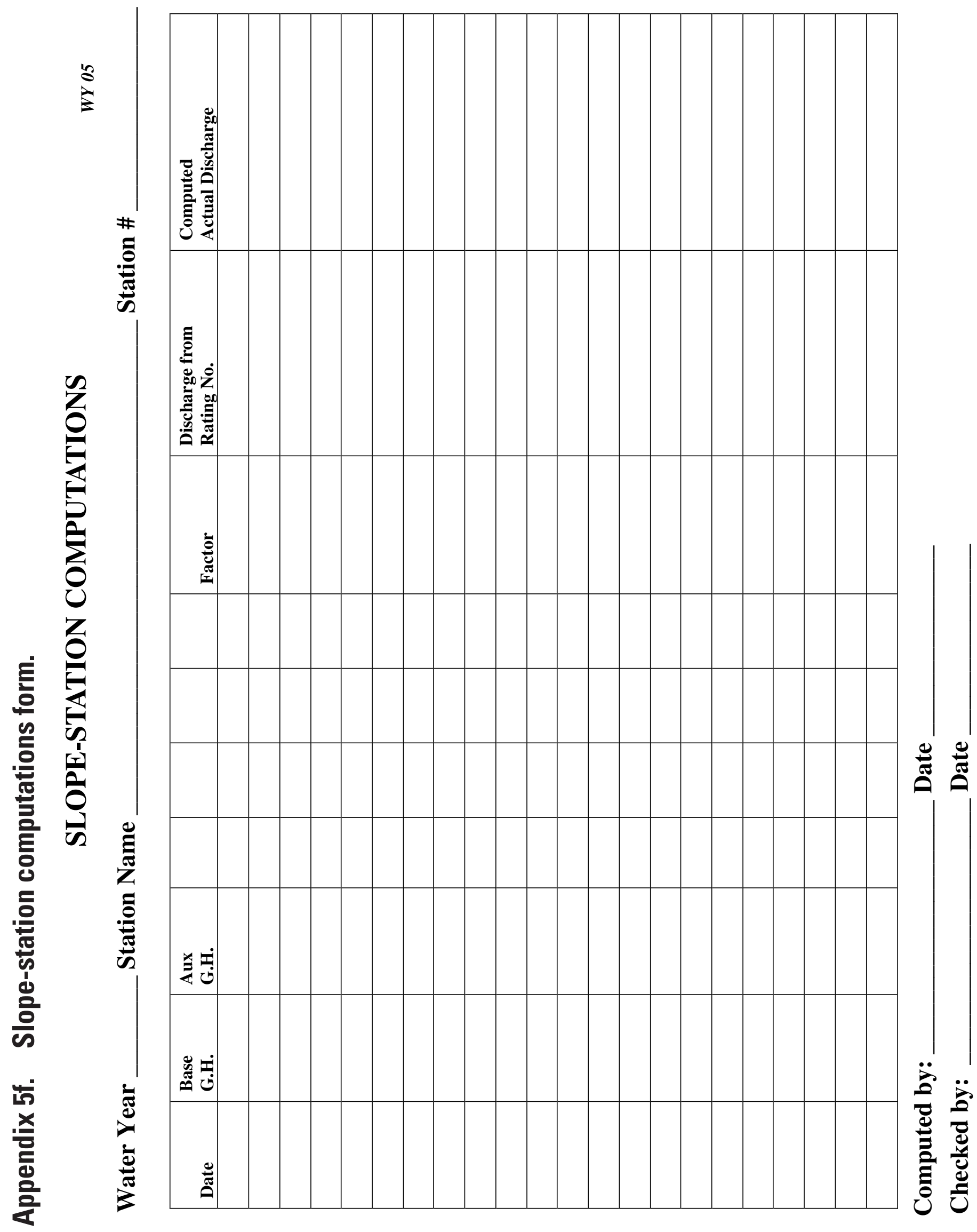




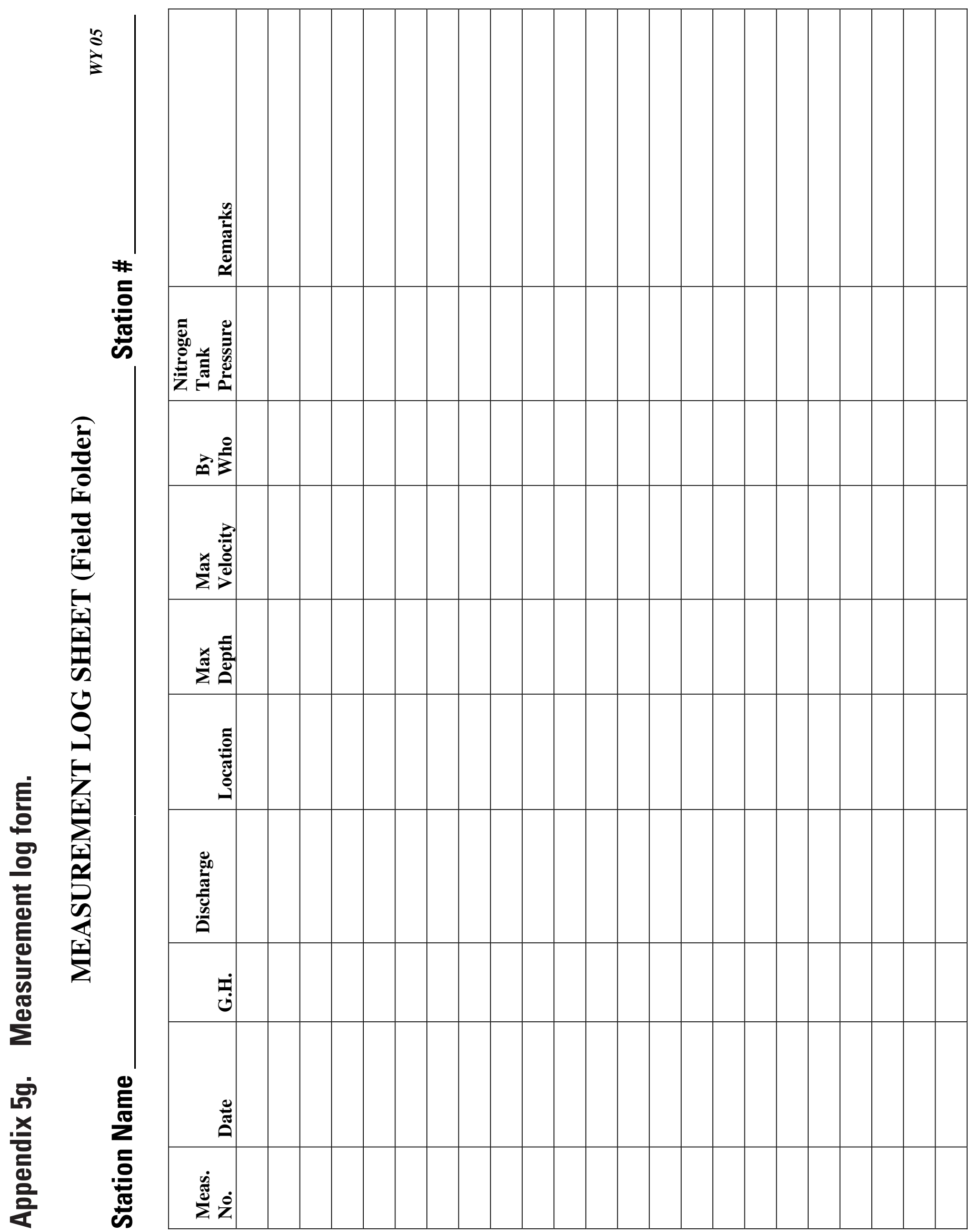




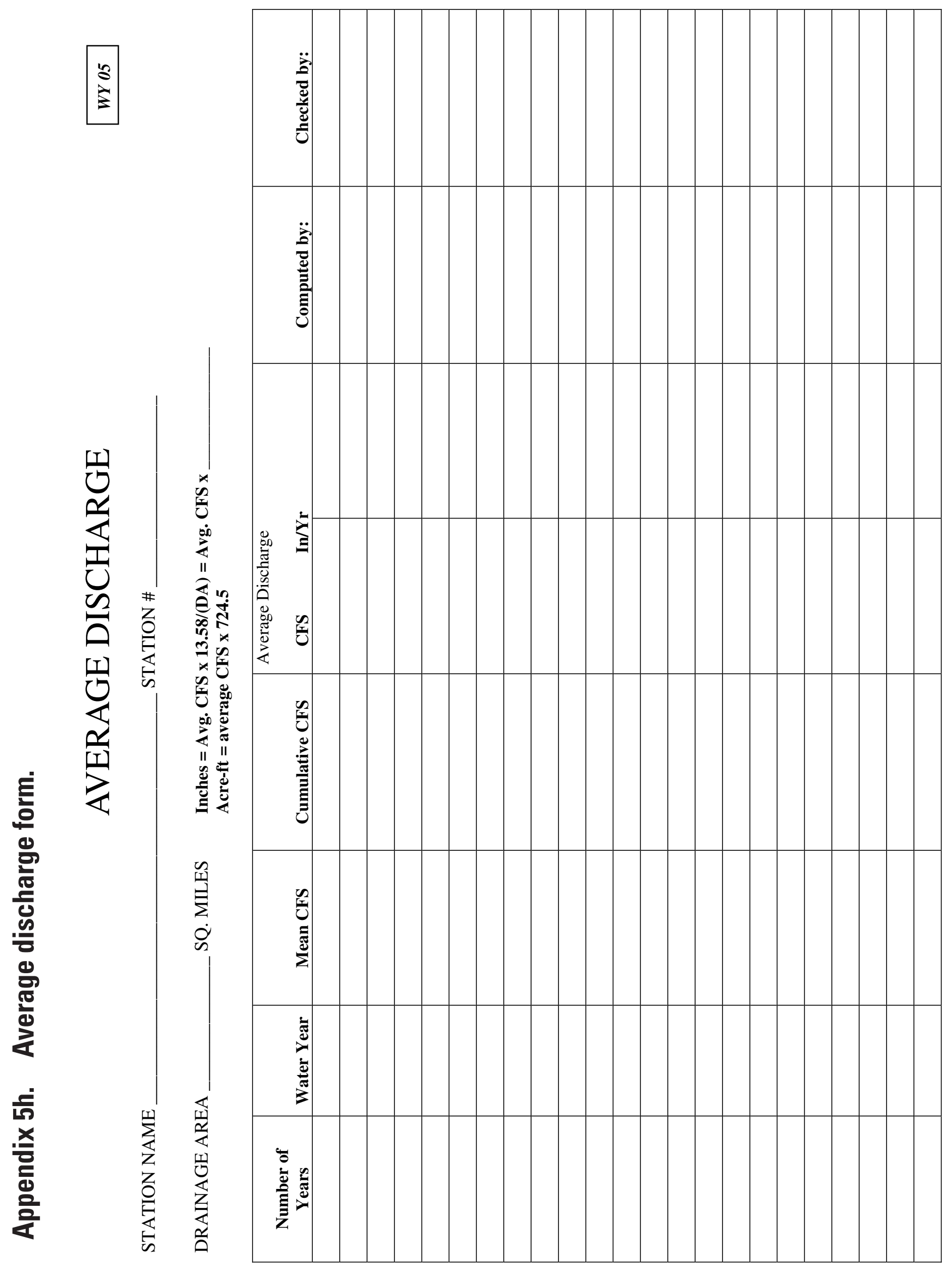




\section{Appendix 6. Hydroacoustic Instrumentation - Standards, Policies, and Procedures.}

This addendum to the Kentucky Water Science Center (KWSC) Surface Water Quality-Assurance Plan presents polices and procedures used by the KWSC specifically related to hydroacoustic instrumentation. Many standards, policies, and procedures documented in the main body of the Surface Water Quality-Assurance Plan apply to the use of hydroacoustics. This addendum documents standards that are unique to the hydroacoustic instruments used by the KWSC. It is expected that this addendum will be updated as the use of hydroacoustics increases and as new instruments, software, and firmware are introduced. This addendum is subdivided by instrument category:

1. Acoustic Doppler Current Profiler

2. Flowtracker Handheld Acoustic Meter

\section{General}

The KWSC Hydrologic Surveillance Section (HSS) chief is responsible for-

1. Updating KWSC users of hydroacoustic instruments on new policies and recommending procedures pertaining to the use of those instruments

2. Updating KWSC users of hydroacoustic instruments on instrument software and hardware upgrades

3. Updating KWSC hydroacoustic quality-assurance documents

4. Making decisions about personnel training pertaining to hydroacoustics

5. Reviewing data, procedures, methods, and documentation regarding hydroacoustics

6. Designating specific KWSC personnel as qualified users of hydroacoustic instruments

\section{Acoustic Doppler Current Profiler (ADCP)}

ADCPs are used by the KWSC to make all types of measurements including the entire range of streamflows. The KWSC has four RD Instruments (RDI) Rio Grande ADCPs (two 1,200 kHz and two $600 \mathrm{kHz}$ ). Two (600 and 1,200 kHz) are kept in the Louisville office. A $1,200 \mathrm{kHz}$ is kept in the Williamsburg field office and the remaining $600 \mathrm{kHz}$ is kept in the Paducah field office. All ADCP operators must read and become familiar with the information contained in the following reports and policy memorandums:

- USGS Open-File Report 95-701, "Quality assurance plan for discharge measurements using broadband acoustic Doppler current profilers," by S.W. Lipscomb, 1995

- USGS Open-File Report 2001-1, “Discharge measurements using a broad-band acoustic Doppler current profiler," by M.R. Simpson, 2002

- USGS Scientific-Investigations Report 2005-5183, "Quality-assurance plan for discharge measurements using acoustic Doppler current profilers,” by K.A. Oberg, S.E. Morlock, and W.S. Caldwell, 2005

- OSW Technical Memorandum 96.02, Interim Policy and Technical Guidance on Broadband ADCPs

- OSW Technical Memorandum 2000.03, Software for Computing Streamflow from Acoustic Profiler Data

- OSW Technical Memorandum 2000.07, National Coordination and Support for Hydroacoustic Activities

- OSW Technical Memorandum 2002.01, Configuration of Acoustic Profilers (RDI) for Measurements of Streamflow 
- OSW Technical Memorandum 2002.02, Policy and Technical Guidance on Discharge Measurements using Acoustic Doppler Current Profilers

- OSW Technical Memorandum 2002.03, Release of WinRiver Software (version 10.03) for Computing Streamflow from Acoustic Profiler Data

- OSW Technical Memorandum 2003.04, Release of WinRiver Software (version 10.05) for Computing Streamflow from Acoustic Profiler Data

- OSW Technical Memorandum 2005.04, Release of WinRiver Software (version 10.06) for Computing Streamflow from Acoustic Profiler Data

\section{ADCP Quality-Assurance File}

The HSS chief maintains the ADCP quality-assurance file. The file is placed in the HSS and contains the following information:

1. A list of ADCPs and serial numbers

2. ADCP maintenance logs

3. Current firmware and software for each ADCP

4. A list of trained operators in the KWSC

5. Quality-assurance logs

6. Archival procedures and examples

7. A processing and reviewing guide

\section{Field Procedures}

1. Prior to going to the field, the ADCP operator ensures that the ADCP is in working order with the latest approved firmware; their notebook computer contains the latest approved software; they have a working laser range finder for measuring edge distances; and they have sufficient space on a compact flash card, CD-R, or USB mediastorage device that is used for temporary backup of the data.

2. Each time the ADCP is used, a diagnostic test is performed and the results are recorded and stored with the measurement data. The filename of the diagnostic test is included on the note sheet of any measurement made with the ADCP.

3. Prior to each measurement, a moving bottom check is performed using an OSW-approved method. The moving bottom check is recorded and archived with the rest of the measurement-data files. The test normally takes 5 to 10 minutes. If a moving bed is found, an OSW-approved method to correct this situation, such as using a differentially corrected GPS, should be used to assist with the data collection.

4. Edge estimates are always measured. Distances are measured using a range finder, tag line, or rule.

5. When using the RDI RIO Grande with the WinRiver software, operators use the Configuration Wizard to set up the instrument for the measurements. If any settings other than the Configuration Wizard settings are used, the reasons for the user settings are explained on the measurement note sheet.

6. The depth to the transducer below water surface is always measured before each measurement.

7. In accordance with OSW requirements, if all of the first four transects are not within 5 percent of the mean of those four measurements, at least four additional transects will be collected. The mean of the eight transects is the final streamflow measurement. Note: There are exceptions for unsteady flow.

8. After each set of measurements, or a least at the end of the day, all measurement data, moving bed tests, and diagnostics tests are backed-up on removable media such as a PC Compact Flash card or a CD. 


\section{Office Procedures (post field)}

ADCP measurements are archived, processed, and reviewed within 5 working days after returning from the field. Data are archived in accordance with the HSS surface-water electronic archiving layout. The layout is located in Appendix 2 of the KWSC Surface Water Quality-Assurance Plan.

The ADCP operator is responsible for archiving all ADCP measurement data, moving bed tests, and diagnostic files; processing all measurements; making sure the measurement data are entered into the KWSC database; and finding a trained ADCP operator to review each measurement.

The reviewer of the ADCP measurement data is responsible for ensuring that correct methods are used to collect and process the measurements. The reviewer ensures that measurement notes are accurate, the data have been archived correctly, and that the measurement notes have been filed. If any changes are made during the review process, the changes should be discussed with the original $\mathrm{ADCP}$ operator, the database updated, and the measurement notes filed.

\section{Flowtracker}

The Sontek Flowtracker is designed for use with a standard USGS top-setting wading rod and used by the KWSC to make wading discharge measurements. The following is a list of recommendations contained in Office of Surface Water Memorandum 2004-04.

\section{Field Measurements}

1. Prior to the use of the Flowtracker, the users must familiarize themselves thoroughly with the instrument by reading the Flowtracker Handheld ADV Technical Documentation. Users should familiarize themselves with the Flowtracker handheld controller, including all keypad operations, prior to collecting field data.

2. Prior to and after a field trip, the users perform a full diagnostic test on the ADV, called the ADVCheck, using the manufacturer's Flowtracker software. The test procedures are described in the operations manual. The software displays signal-strength plots for each ADV receiving transducer. The Flowtracker Operations Manual describes the ADV Check and provides examples of good and problem signal-strength plots. If the signal-strength plots indicate a possible malfunction, the Flowtracker is not used to collect field data. In all instances, every diagnostic test is logged to a file. All diagnostic files and measurement data are archived electronically using the HSS surface-water electronic archiving layout as documented in Appendix 2 of the KWSC Surface Water QualityAssurance Plan. The diagnostic and measurement files can be provided to the manufacture for troubleshooting the instrument if problems occur. Anytime there is a malfunction or a problem occurs, an ADVCheck is performed prior to further data collection.

3. Prior to each discharge measurement, the user checks the ADV using the handheld controller Systems Functions Menu. The following items are checked:

- System clock - The clock displays the correct date and time.

- Recorder status - There is adequate data-storage capacity for the discharge measurement or velocity data run.

- Temperature data - The ADV probe is immersed in the stream and the temperature is noted. At least once daily, the temperature recorded by the Flowtracker is checked against a temperature reading from an independent source. The temperature is noted on the discharge measurement note sheet.

- Battery data - The battery voltage is checked to ensure adequate capacity for the discharge measurement.

4. The Flowtracker is designed for mounting on a standard top-setting USGS wading rod. It is recommended that an offset bracket available from the manufacturer or the Hydrologic Instrumentation Facility (HIF) be used to mount the Flowtracker probe head to the wading rod. The KWSC uses the offset bracket, which allows the sample volume to be located about 2 in. from the wading rod. The bracket was designed to move the sample volume as close to the wading rod as possible while remaining outside the flow disturbance caused by the wading rod. 
5. The Flowtracker probe head should be oriented so that the longitudinal axis passing through the centertransmitting transducer is parallel to the tagline, and the receiving arm with the red band should be downstream. Every effort is made to hold the wading rod level so the sample volume does not strike a boundary such as the streambed.

6. The minimum recommended velocity threshold for the Flowtracker is $0.1 \mathrm{ft} / \mathrm{s}$; the instrument velocity error at $0.1 \mathrm{ft} / \mathrm{s}$ is approximately 4 percent. If measured velocities are less than $0.1 \mathrm{ft} / \mathrm{s}$, the measurement is not rated better than "fair."

7. The measurement data from the Flowtracker after each set of measurements, or a least at the end of the day, including all measurement data, temperature tests, and the ADV Check diagnostic tests are backed-up on removable media such as a PC Compact Flash card or a CD.

8. Standard USGS measurement note sheets may be used to document the discharge measurement.

\section{Measurement Documentation}

For each set of discharge measurements, a file with the WAD extension is generated and stored on the handheld controller. The .WAD file is downloaded from the controller, then the Flowtracker software is used to extract the following four files from the WAD file:

- .CTL file - an ASCII file containing the Flowtracker configuration

- .DAT file - an ASCII file containing 1-second velocity component and signal-to-noise ratios

- .SUM file - an ASCII file containing station information and summary statistics from each measurement

- .DIS file - an ASCII file containing a discharge-measurement summary

A paper copy of the .DIS file is printed and attached to the measurement note sheet for filing. All four extracted electronic files plus the .WAD file are archived, processed, and reviewed within 5 working days after returning from the field. Data are archived in accordance with the HSS surface-water electronic archiving layout. The layout is located in Appendix 2 of the KWSC Surface Water Quality-Assurance Plan.

\section{Measurement Quality Assurance}

The following is a list of recommendations for using Flowtracker parameters to help assess the quality of the discharge measurements. Guidelines for using the parameters are-

- Velocity standard error - If the average standard error for the measurement exceeds 8 percent of the mean measurement velocity, the measurement is rated no better than "fair." If the standard error exceeds 10 percent of the mean measurement velocity, the measurement is rated no better than "poor."

- Boundary flag - There are four possible flags assigned to each station: "best," "good," "fair," and "poor." A boundary flag of "best' does not guarantee a lack of boundary interference (see the Flowtracker Technical Documentation). If the ADV sample volume was striking a solid boundary, a 'best' flag likely would be displayed, but the measured discharge could be biased toward zero.

- Velocity spikes - An excessive number of velocity spikes (more than 10 spikes per measurement) could be reason to downgrade the quality of the measurement.

- Flow angles - A good measurement section shows some flow-angle variations. Angles less than 20 degrees depict a good measurement.

- DatView - The use of the DatView software is used prior to making streamflow measurements, and the information collected during this test is logged and archived with the raw measurement data. 


\section{Periodic Quality-Assurance Checks}

Each Flowtracker is checked for discharge-measurement accuracy annually and after any hardware or firmware changes. The check consists of making a discharge measurement at a site where the Flowtracker-measured discharge is compared with a known discharge derived from some other source. Appropriate sources of comparison discharge would be discharge obtained from a stable discharge rating or discharge measured with a second Flowtracker or mechanical meter known to meet USGS calibration standards. 



\section{$\frac{1}{50}$}

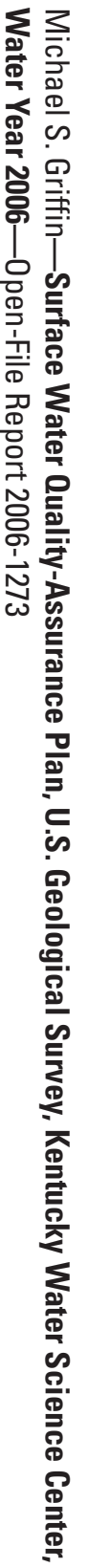

69 Printed on recycled paper 